\title{
Wind Climate in Kongsfjorden, Svalbard, and Attribution of Leading Wind Driving Mechanisms through Turbulence-Resolving Simulations
}

\author{
Igor Esau ${ }^{1,2}$ and Irina Repina ${ }^{3}$ \\ ${ }^{1}$ Nansen Environmental and Remote Sensing Centre, G.C. Rieber Climate Institute, 5006 Bergen, Norway \\ ${ }^{2}$ Centre for Climate Dynamics, 5020 Bergen, Norway \\ ${ }^{3}$ Obukhov Institute for Atmospheric Physics, Russian Academy of Sciences, 119017 Moscow, Russia
}

Correspondence should be addressed to Igor Esau, igore@nersc.no

Received 31 October 2011; Revised 28 January 2012; Accepted 22 February 2012

Academic Editor: Anna Sjöblom

Copyright (C) 2012 I. Esau and I. Repina. This is an open access article distributed under the Creative Commons Attribution License, which permits unrestricted use, distribution, and reproduction in any medium, provided the original work is properly cited.

This paper presents analysis of wind climate of the Kongsfjorden-Kongsvegen valley, Svalbard. The Kongsfjorden-Kongsvegen valley is relatively densely covered with meteorological observations, which facilitate joint statistical analysis of the turbulent surface layer structure and the structure of the higher atmospheric layers. Wind direction diagrams reveal strong wind channeled in the surface layer up to $300 \mathrm{~m}$ to $500 \mathrm{~m}$. The probability analysis links strong wind channeling and cold temperature anomalies in the surface layer. To explain these links, previous studies suggested the katabatic wind flow mechanism as the leading driver responsible for the observed wind climatology. In this paper, idealized turbulence-resolving simulations are used to distinct between different wind driving mechanisms. The simulations were performed with the real surface topography at resolution of about $60 \mathrm{~m}$. These simulations resolve the obstacle-induced turbulence and the turbulence in the non-stratified boundary layer core. The simulations suggest the leading roles of the thermal land-sea breeze circulation and the mechanical wind channeling in the modulation of the valley winds. The characteristic signatures of the developed down-slope gravity-accelerated flow, that is, the katabatic wind, were found to be of lesser significance under typical meteorological conditions in the valley.

\section{Introduction}

Understanding of driving mechanisms shaping wind climate of the Arctic is important to a number of different research and applied problems, the regional weather forecast, planning of industrial activity, and better health care of the local population. In particular, strong and persistent surface winds in the western part of Svalbard can significantly alter ocean and sea ice processes [1] and climate of the larger region in the key Atlantic sector of the Arctic [2]. Unfortunately, the network of meteorological stations, which provide information to characterize the wind climate, is rather sparse in the Arctic. Therefore, the long-term, consistent, and relatively diverse observations in the Kongsfjorden-Kongsvegen valley (see Figure 1) are valuable for research on the detection and attribution of specific feature of the wind climate in a typical
Arctic fjord. Similar fjords with steep slopes and glaciers are found in Greenland and in many other places in the Arctic.

The major observed feature of the Arctic fjord wind climate can be described as surface winds, which blow along the axis of the fjord. The wind climate of the KongsfjordenKongsvegen valley (hereafter referred to as the valley) exhibits this feature very clearly (e.g., [3-9]). Hanssen-Bauer et al. [3], Førland et al. [4], and Hartmann et al. [5] compiled a general description of the Svalbard wind climate on the basis of ground-born meteorological observations. They emphasized the typically observed wind channeling in the valley and other Arctic fjords but did not provide the details of the wind climate. Beine et al. [7] and Argentini et al. [9] studies are more specific as they were based on the results of field measurement campaigns. In particular, the wind roses for different months and for different elevations up to $500 \mathrm{~m}$ 


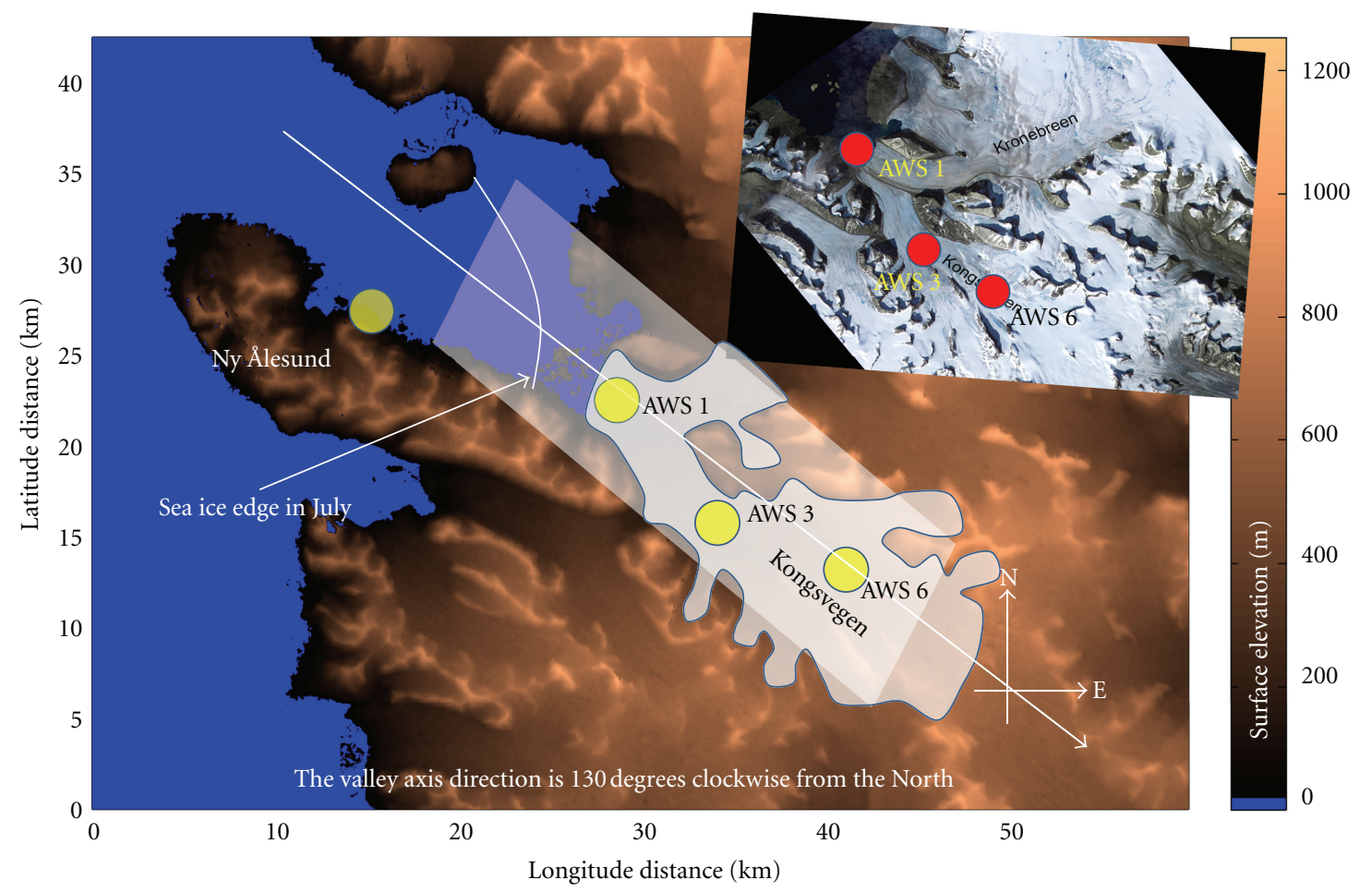

FIGURE 1: The scheme of the Kongsfjorden-Kongsvegen area with the research station Ny-Ålesund and the automatic weather station (AWS) sites on the glacier. The surface elevation is taken from the digital elevation model ASTER. The satellite image is courtesy of Andy Kääb. The domain of PALM simulations is shown with the semitransparent rectangle.

(at Zeppelin Mountain) were presented. The wind channeling was found for all months and at all heights but during the summer months this channeling was less pronounced. Similar conclusions were drawn in Erath [10], Krismer [11], and Livik [12] studies based on analysis of the AWS data. The reviewed studies used different combinations of the available surface data sets, which were collected at different locations and heights and during different time periods. Despite those differences, the surface wind channeling and alignment with the valley axis remain the dominant wind features in the data.

The studies of the surface layer wind based on the highquality but short-term observations are however not sufficient to characterize the wind climate, its vertical structure, and its driving mechanisms. Therefore, there were several modeling studies dealing with one or several aspects of the Svalbard regional climate. Here, we review only those studies where the model resolution was sufficiently fine to resolve some typical features of the Svalbard relief. Skeie and Grønås [6] simulated strongly stratified easterly flow across the Svalbard archipelago with a numerical model with a grid distance of $10 \mathrm{~km}$. They found pronounced wind wakes with high velocity to downstream from the valleys. Later this feature was confirmed by simulations and satellite image analysis in Sandvik and Furevik [2]. The wind wakes were originated from the three resolved fjords Isfjorden, van Mijenfjorden, and Hornsund. The wind speed in the wakes was by factors of 1.7 to 2.2 higher than the wind speed in the undisturbed flow. Skeie and Grønås [6] attributed this acceleration to the gravity wave activity and the large-scale left-right asymmetry induced by planetary rotation. The model resolution in Kilpeläinen et al. [13] study was significantly refined. The study did not aim to perform simulations of climatologically typical cases. Instead, ten real cases from winter and spring 2008 were simulated at 9,3 , and $1 \mathrm{~km}$ resolutions for $36 \mathrm{~h}$ each. Fairly good agreement with observations was demonstrated, although a systematic warm and moist bias and slightly overestimated wind speeds were found close to the surface. One should note that even the model resolution of $1 \mathrm{~km}$ does not represent properly the valley and steep surrounding mountains. Moreover, the model simulations included the complicated combinations of physical and advective driving factors, as it is usually found in the simulations of the realistic cases, which limit the extend of attribution studies. Nevertheless, Kilpeläinen et al. [13] concluded that the spatial variability of the surface fluxes of sensible and latent heat was mostly controlled by the air and sea surface temperatures instead of wind speed. The influence of the realistic topography on meteorological quantities was not systematic, except that a clear warming effect was seen in all the fjords studied. These conclusions are confirmed in Livik [12] simulations centered on the Kongsfjorden-Kongsvegen valley. Livik [12] model study is the attribution study with the Weather Research and Forecast model (WRF) run at resolution of $1 \mathrm{~km}$. The simulations were performed for different flow regimes 
assumingly associated with the katabatic wind and the katabatic wind with different patterns of large-scale advection. This study includes also detailed comparisons between the model and observational results for the studied cases. Livik focused the discussion of the differences in the wind structures in topographically deflected flows and the pure katabatic flows. He concludes that the poor katabatic flows are the leading wind driving mechanism in the valley.

The aforementioned very brief review shows that there is a reasonable agreement between the surface data sets on the spatial and temporal structure of the valley winds. The consistent wind channeling features were clearly identified in all data sets. The attributions of the wind driving mechanisms in the model studies, however, diverged. The most detailed study by Livik [12] criticized the earlier intuitive attributions of the driving mechanisms. It compares the mechanical wind channeling of the flow and the katabatic flow mechanisms. Despite certain inconsistency of the model results with observations and the katabatic wind theory, it was concluded that the katabatic wind mechanism is the leading driving mechanism shaping the wind climate of the valley.

One should note that the reviewed studies are incomplete in two aspects. Firstly, the earlier studies were based on short data sets or even on a few specifically selected cases. Moreover, they did not consider the climatology of the wind and temperature vertical structures. Hence, they did not disclosed typical free atmosphere conditions associated with the observed combination of the meteorological parameters in the surface layer where the wind variability is naturally very limited. Secondly, the attribution studies did not consider one of the strongest thermal circulations, namely, the circulation caused by the horizontal difference in the land and sea surface temperatures. This difference will drive the valley wind even in the case of negligible surface vertical heat flux divergence.

In this study, we advance the description of the valley wind climate and the statistical detection of certain specific features in it. We use primarily the observations from the Integrated Global Radiosonde Archive (IGRA; available on $\mathrm{ftp} / / / \mathrm{ftp} . n c d c . n o a a . g o v /$ pub/data/igra/data-por) made at the station Ny-Ålesund. The IGRA data analysis complements the previous studies, which have been based on the data collected by the automatic weather stations (AWS) on the glacier $[10,11]$ and along the fjord coast $[12,13]$. The IGRA data also characterize the wind climate at higher elevations and over longer period of time than AWS and episodic field campaigns [9] do. In contrast to previous studies, our work includes also a composite analysis of the wind-temperature structure at different levels and for different seasons. It gives a chance to recognize specific signatures of one or another driving mechanism directly in the data statistics.

The wind field in the valley is likely created by a complex interplay of different mechanisms where the commonly accepted katabatic wind mechanism may not be leading or even important. Presence of large mountain glaciers in the valley is frequently referred to as one of the reasons to invoke the katabatic wind mechanism for explanation of observed and simulated wind features [12, 15-19]. In particular, Oerlemans and Grisogono [18] analyzed different mounting glaciers in Switzeland, Iceland, and West Greenland to conclude that the katabatic wind is very common in all three valleys and rarely disrupted by the large-scale flow. Indeed, the observed vertical structure of the wind profiles looks similar to the structure predicted by the theory of the phenomenon of the equilibrium gravity-accelerated dense current over an infinite inclined surface (e.g., [20,21]). However, winds in a valley are always channeled. Hence, the qualitative similarity is not sufficient for reliable attribution of the driving mechanisms. In fact the qualitative analogy to the katabatic winds in Greenland and Antarctica is deficient due to rather small length (just about $50 \mathrm{~km}$ ) of the mountain glaciers. England and McNider [22] derived a quadratic asymptotic estimation of the maximum katabatic wind speed in the neutrally stratified atmosphere as function of the glacier length. The katabatic wind speed for the Svalbard glaciers according to the England and McNider [22] formula should be less than $5 \mathrm{~m} \mathrm{~s}^{-1}$.

It is not only the down-slope gravity acceleration of an air mass cooled at the surface, that is, the katabatic wind mechanism, which can create strong surface winds in the valley. Another common mechanism, which has been missed in the Arctic studies, is the thermally driven land-sea breeze circulation. The breeze is created by the horizontal temperature difference between the open water fjord and the glacier. Kilpeläinen et al. [13] study indicates that the mountains increase this difference and therefore strengthen the breeze circulations. Furthermore, the topography can cause purely mechanical effects on the wind $[6,14,23]$ like channeling, drainage, and gravity waves, which do not require the density difference to drive the flow.

In a series of publications, Doran with coauthors developed methodology of wind direction phase diagrams, which has been later successfully applied to attribute the mechanisms driving the valley flow under different climate conditions. Doran [14] numerical study demonstrated that the air forced into the valley by the mean pressure gradient (by the geostrophic wind) must induce the surface current in the opposite (down-slope) direction. Whiteman and Doran [24] applied the diagrams based on directions of the surface and the geostrophic winds to distinguish between four different mechanisms driving the valley flow. These authors studied the wind channeling in the Tennessee River valley, which is covered with observations much denser than the Arctic fjord valley under consideration. Cogliati and Mazzeo [25] applied the diagrams to study the valley wind climate utilizing only a limited number of observations. Recently, Nawri and Harstveit [26] have applied the diagrams to study the wind climate and to attribute the wind driving mechanisms in the Northern Norwegian fjords in Finnmark. In particular, they concluded that a clear separation between different prevailing surface wind directions in each season can be achieved based exclusively on the local mean sea level geostrophic wind direction. During the warm season, downward mixing of westerly overlying winds becomes more important as the stability of the boundary layer stratification decreases. 
In this study, we advance the attribution of the revealed statistical features in the valley wind climate with fine resolution numerical simulations. We utilized the turbulenceresolving model Parallelized Atmospheric Large-eddy Model (PALM) described in Letzel et al. [27]. The PALM simulations are more suitable for the attribution studies than the regular WRF simulations as PALM is easy to set up for one particular driving mechanism at time. Moreover, PALM resolution is of two orders of magnitude finer than the achieved WRF resolution. Therefore not only the model topography is more realistic (especially slopes in the valley) but also the turbulence is partially resolved. We will elaborate this statement in the paper. The model topography with horizontal resolution of about $60 \mathrm{~m}$ is shown in Figure 1. The digital elevation model (DEM) is taken from the Advanced Spaceborne Thermal Emission and Reflection Radiometer (ASTER; available from http://www.gdem.aster.ersdac.or.jp/).

This paper consists of three research sections. Section 2 reports wind climatology based on the IGRA data and compares it with the published AWS data and results of field campaigns. This section constitutes the detection part of the study. Section 3 constitutes the attribution part of the study. This section describes the numerical experiments with PALM. It highlights specific features in the wind structure associated with different driving mechanisms. Section 4 concludes the study combining the results of the statistical analysis of the wind climatology with the model attribution study.

\section{Wind Climatology}

2.1. Wind Climatology from the Data Archive IGRA. The Kongsfjorden-Kongsvegen valley (see Figure 1) is relatively densely covered with observations, and therefore, the valley is one of a few well-studied places of the Svalbard archipelago as well as among other Arctic fjords. The longest atmospheric observations are provided by the radiosounding station in $\mathrm{Ny}$-Ålesund. In order to establish the wind climatology in the valley, we utilized the observations from the Integrated Global Radiosonde Archive (IGRA; available on ftp://ftp .ncdc.noaa.gov/pub/data/igra/data-por). IGRA is a quality controlled archive [28] with data available at the standard pressure levels $(1000,925,850,700,500,400,300,250,200$, $150,100 \mathrm{hPa})$, the surface, the tropopause, and several significant levels in the atmosphere. The available meteorological parameters are the temperature, the geopotential height, the dew point depression, and the wind direction and speed. The Ny-Ålesund station has the World Meteorological Organization identifier 01004 . It is located at $78.9 \mathrm{~N}$ and $11.9 \mathrm{E}$. The archive contains 5396 soundings, which is $76.5 \%$ of the theoretically possible amount $[29,30]$. Thus, the observational record is rather complete. The data are available for the period 1993-2008. In this study, we use only the data at the standard pressure levels and at the surface.

The Ny-Ålesund wind climatology computed for the period 1993-2008 is shown in Figure 2. The surface wind channeling is clearly seen on the plot where the median wind direction is shown by arrows. The wind directions at the surface level and, to some degree, at the $925 \mathrm{hPa}$ pressure level are limited to the sector 100-160 degrees (clockwise from the North). These directions correspond to the wind from the South-East along the major axis of the valley. On average, the summertime and wintertime wind directions are slightly different but remain within this sector. Wind directions at the higher pressure levels change dramatically. The most probable (median) wind directions at the $700 \mathrm{hPa}$ pressure level become nearly 270 degrees, which correspond to the westerly winds. The mean surface pressure in Ny-Ålesund is $1009 \mathrm{hPa}$. The mean height of the $925 \mathrm{hPa}$ surface is about $700 \mathrm{~m}$. Thus, the layer of the strongly channeled winds is comparable in thickness with the height of the surrounding mountains ( $800 \mathrm{~m}$ to $1200 \mathrm{~m}$ ). The wind channeling is persistent throughout the year. In wintertime, the significant change of the wind direction is found near the $850 \mathrm{hPa}$ pressure level at about $1.5 \mathrm{~km}$ height. In summertime, the layer of the channeled winds is thinner. The wind direction changes already at $700 \mathrm{~m}$. The obtained wind climatology is consistent with analysis of the short-term data sets for MarchSeptember 1998 during the Arctic Radiation and Turbulence Interaction Study (ARTIST) reported by Beine et al. [7] and Argentini et al. [9]. These authors also observed significant changes in the wind direction between $300 \mathrm{~m}$ and $500 \mathrm{~m}$ in the ARTIST data for April.

The more detailed analysis of the structural feature of the wind climatology is obtained through development of the wind diagram methodology previously utilized in Cogliati and Mazzeo [25] and Nawri and Harstveit [26]. Probabilities to find certain wind direction at two levels in the atmosphere are shown in Figure 3. The winds at the $700 \mathrm{hPa}$ pressure level (at about $3 \mathrm{~km}$ above the sea level) have the maximum probability to blow from the western sectors. The surface winds are constraint by the valley and exhibit the much larger probabilities to blow along the valley. It is noteworthy that wind direction alignment throughout the entire $3 \mathrm{~km}$ layer of the atmosphere is the least probable for the directions close to the direction of the axis of the valley. Figure 4 discloses that strong winds are those channeled the most. As expected, the strongest winds at the surface are aligned with the valley axis. It is surprising, however, that the directions of the strong winds at the $700 \mathrm{hPa}$ pressure level are opposite to the directions of the surface strong winds. Figure 5 complements this description. It shows the typical (mean) wind speed at the surface and at the $700 \mathrm{hPa}$ pressure level as well as the median angle between the surface and the $700 \mathrm{hPa}$ level wind directions for all four seasons. The channeled wind is stronger than the wind in other sectors for all seasons but summer. The strong surface winds do not necessarily correspond to the equally strong winds at higher elevations. Moreover, the surface winds are on average rotated by 90 to 120 degrees with respect to the winds in the free atmosphere.

The analysis given in Figures $2-5$ supports the conclusion that the dominant surface winds in the valley are strongly channeled but not driven by the similar wind at higher altitudes. Contrary, the surface winds frequently blow in the opposite direction to the geostrophic winds in the free atmosphere. The $850 \mathrm{hPa}$ pressure level does not have any dominant direction of the wind. It allows identification of this or adjacent levels as the top of the layer of channeled winds. 

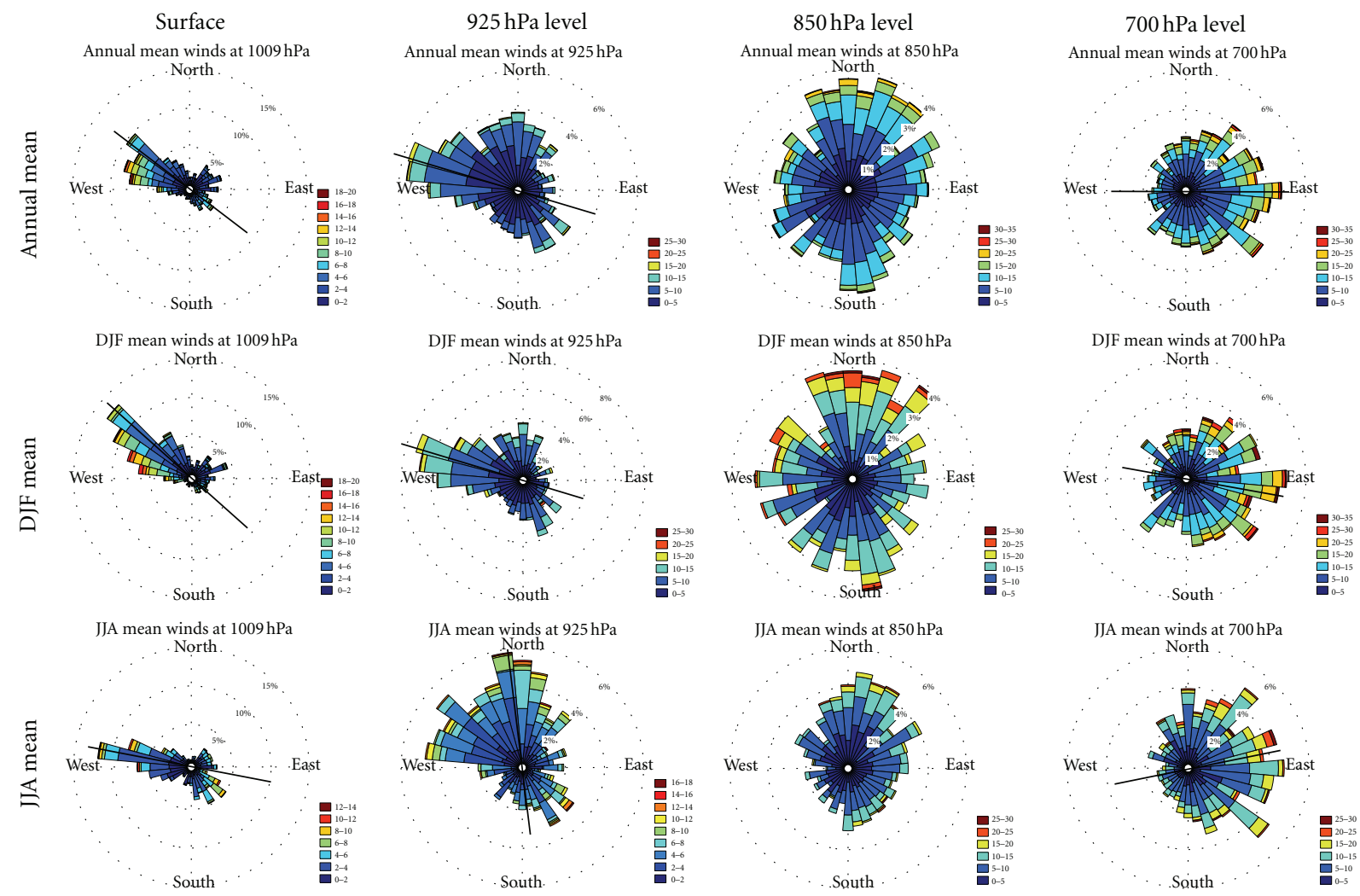

FIgURE 2: The wind climatology for the Ny-Ålesund station as obtained from the IGRA data archive for the period 1993-2008. The wind speed climatology is shown with color; wind direction, with the orientation of the bars; and probability, with the size of the bars. Arrows show the median wind vectors.

Hence, the wind channeling can be recognized up to $1000 \mathrm{~m}$ height.

To our opinion such a deep layer cannot be attributed to the effect of the katabatic winds. The theory of the katabatic wind $[16-18,21]$ suggests that the layer of significant katabatic wind should be rather shallow. Indeed, the katabatic wind mechanism implies that the dense air layer is created by the intense surface cooling, which means that this layer must be stably stratified. The vertical turbulent mixing in the stably stratified layers is suppressed (e.g., $[31,32]$ ). Hence, the air is cooled significantly only in a thin (a few tens of meters) layer near the surface. On an inclined surface, this relatively dense but shallow layer will be accelerated down-slope by the gravity force. Above this surface layer, the air temperature is little affected by the cooling. Moreover, the weak turbulent friction cannot redistribute enough momentum from the accelerated layer below. Exactly this pattern is observed in Antarctica and Greenland where the katabatic wind is common (e.g., [33]). Hence, the air above a few tens of meters from the surface should not reveal significant movement, especially under the conditions of the opposite geostrophic wind.

2.2. Wind Climatology from Surface Layer Observations. The surface layer data sets are more diverse in the valley. The data sets include the regular observations in Ny-Ålesund available since 1974, several AWS in continues operation over several years, and more short-term data sources operated during field campaigns, mostly during spring and summertime. Table 1 provides information about some of these data sources. There are also a number of short-term installations (Zeppelin, Pynten, Austre, Gåsebu, Brandal, Stupbekken; see [12]), which are not reviewed in this study. Our own analysis is focused on the AWS 3 and Ny-Ålesund data records, whereas AWS 1 and AWS 6 results are taken from Krismer [11]. The AWS 3 carried out the measurements on a flat surface with no obstacles nearby. The station instrumentation consisted of the Metek ultrasonic thermometer-anemometer (model USA-1) mounted on top of a $2 \mathrm{~m}$ mast, the Kipp\&Zonen net radiometer (model CNR1), and the meteorological station.

The composite analysis of the surface meteorological data from Ny-Ålesund is shown in Figure 6. The diagram in the parameter phase space defines the position of each measurement through the triplet: the wind speed, $U$, the wind direction, $D$, and the temperature, $T$. The parameter phase space is then divided on $N=20$ bins along each axis. Hence, the parameter phase space is covered with $N$ by $N$ squares. All data points inside each square are averaged to obtain the mean values of the triplets $\bar{U}, \bar{D}$, and $\bar{T}$. Then $\bar{T}$ is shown in colors and $\bar{U}$ and $\bar{D}$ as two orthogonal axes. The contour lines show the relative number of measurements found in each square, that is, the relative probability to find the given combination of those three meteorological parameters in 


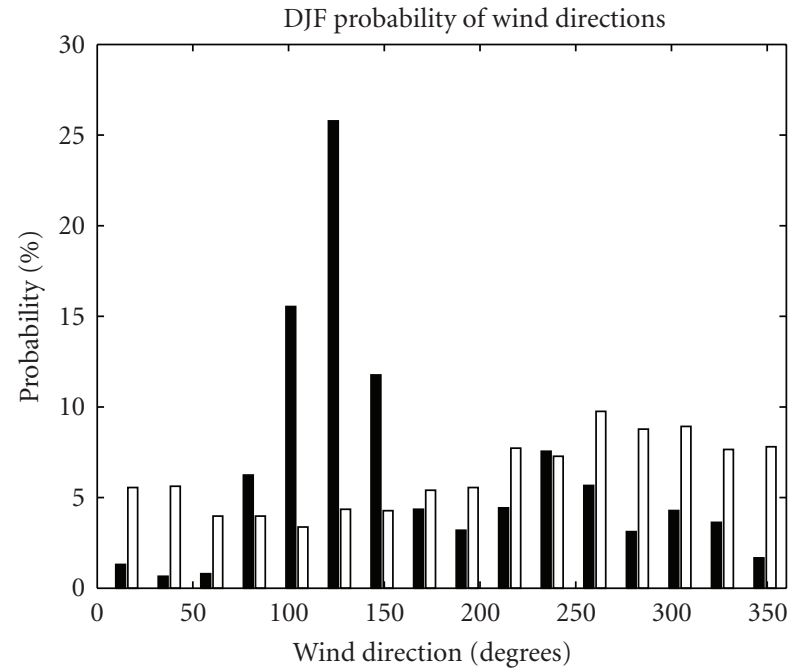

(a)

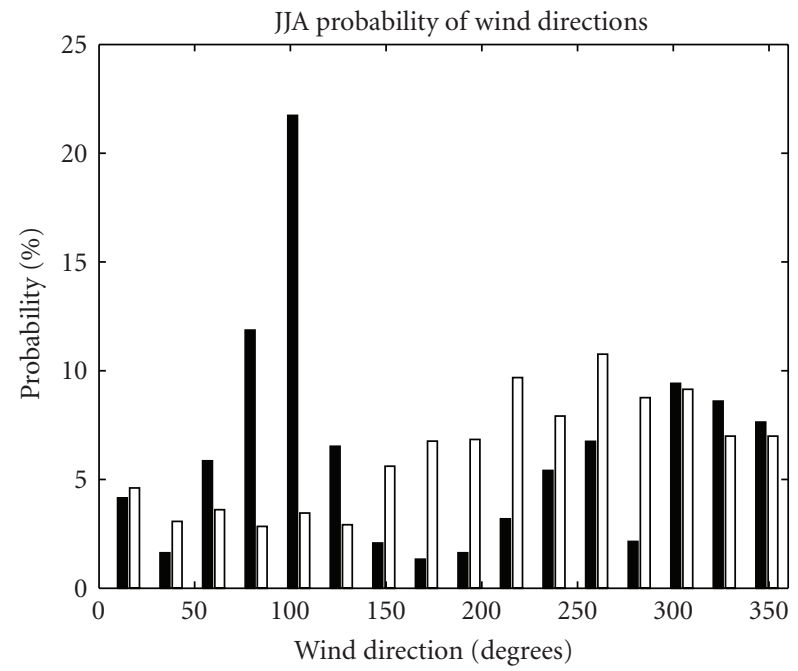

(c)

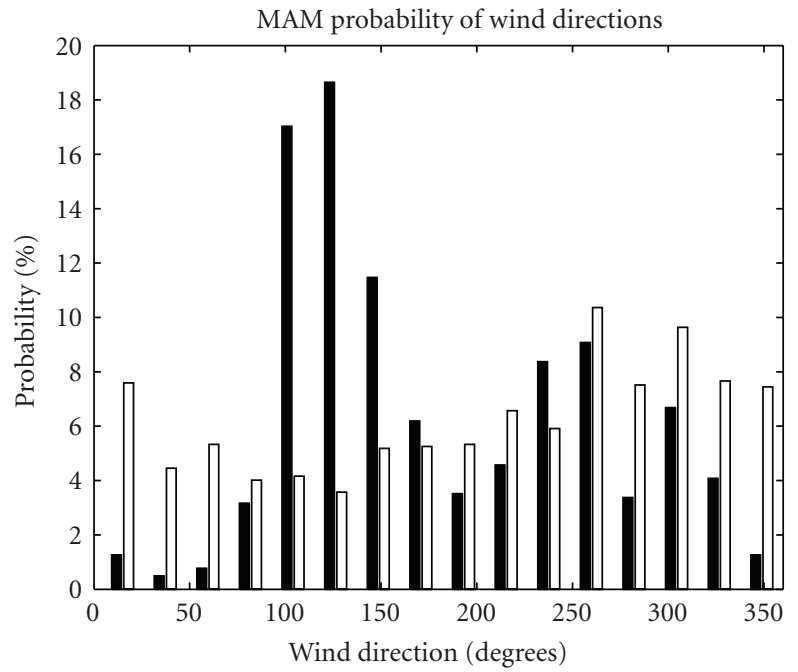

(b)

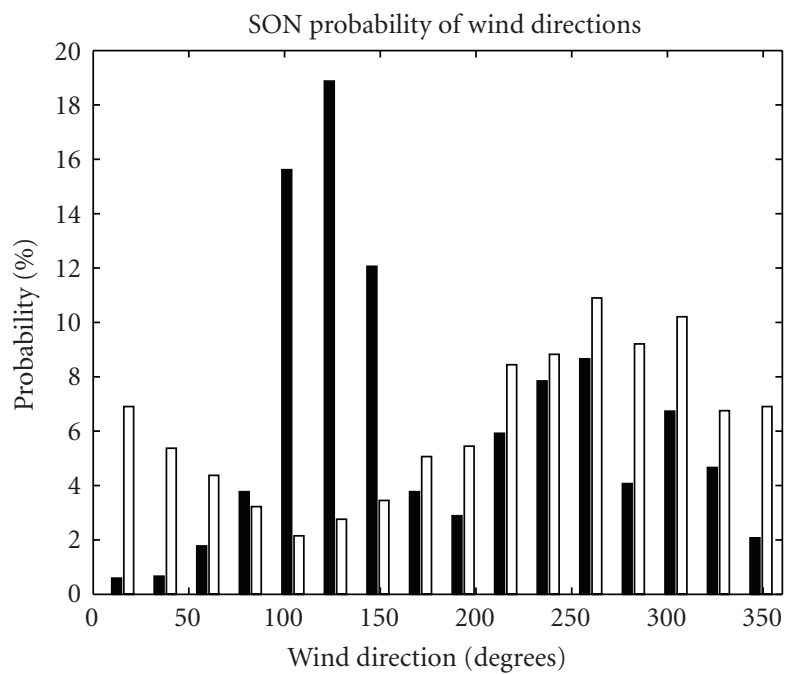

(d)

FIGURE 3: The climatological probability of wind directions in Ny-Ålesund from the IGRA data archive for four seasons: winter (a), spring (b), summer (c), and autumn (d). The black bars correspond to the probability of the surface winds, and the white bars to the winds at the $700 \mathrm{hPa}$ pressure level.

TABLE 1: Sources of the meteorological data in the Kongsfjorden-Kongsvegen valley.

\begin{tabular}{|c|c|c|c|c|}
\hline Station & Coordinates & Maintenance & Observations & Period \\
\hline Ny-Ålesund & $\begin{array}{c}8 \mathrm{~m} \text { a.s.l. } \\
78.9230 \mathrm{~N} \\
11.9333 \mathrm{E}\end{array}$ & $\begin{array}{l}\text { WMO station } 99910 \\
\text { eKlima@met.no }\end{array}$ & $\begin{array}{l}\text { Regular meteorological } \\
\text { observations }\end{array}$ & 06.1974-to date \\
\hline AWS 1 (Glacier margin) & $170 \mathrm{~m}$ a.s.l. & $\begin{array}{l}\text { Institute of Meteorology and } \\
\text { Geophysics Innsbruck (IMGI) and } \\
\text { the Norwegian Polar Institute (NPI) }\end{array}$ & $\begin{array}{l}\text { Temperature, wind speed and } \\
\text { direction, relative humidity, global } \\
\text { and reflected short-wave radiation, } \\
\text { atmospheric and surface long-wave } \\
\text { radiation }\end{array}$ & 05.2007-06.2008 \\
\hline AWS 3 & $350 \mathrm{~m}$ a.s.l. & $\begin{array}{l}\text { Obukhov Institute for Atmospheric } \\
\text { Physics (IAP) and the Institute for } \\
\text { Marine and Atmospheric Research, } \\
\text { Utrecht University }\end{array}$ & $\begin{array}{l}\text { The same; in addition } 15 \mathrm{~m} \\
\text { gradient mast and a number of } \\
\text { remote sensing instruments } \\
\text { including SODAR were installed }\end{array}$ & 05.2009-to date \\
\hline $\begin{array}{l}\text { AWS } 6 \text { (equilibrium } \\
\text { altitude of the glacier) }\end{array}$ & $550 \mathrm{~m}$ a.s.l. & $\begin{array}{l}\text { Institute of Meteorology and } \\
\text { Geophysics Innsbruck (IMGI) and } \\
\text { the Norwegian Polar Institute (NPI) }\end{array}$ & The same & $\begin{array}{l}05.2000-02.2006 \\
05.2007-\text { to date }\end{array}$ \\
\hline
\end{tabular}




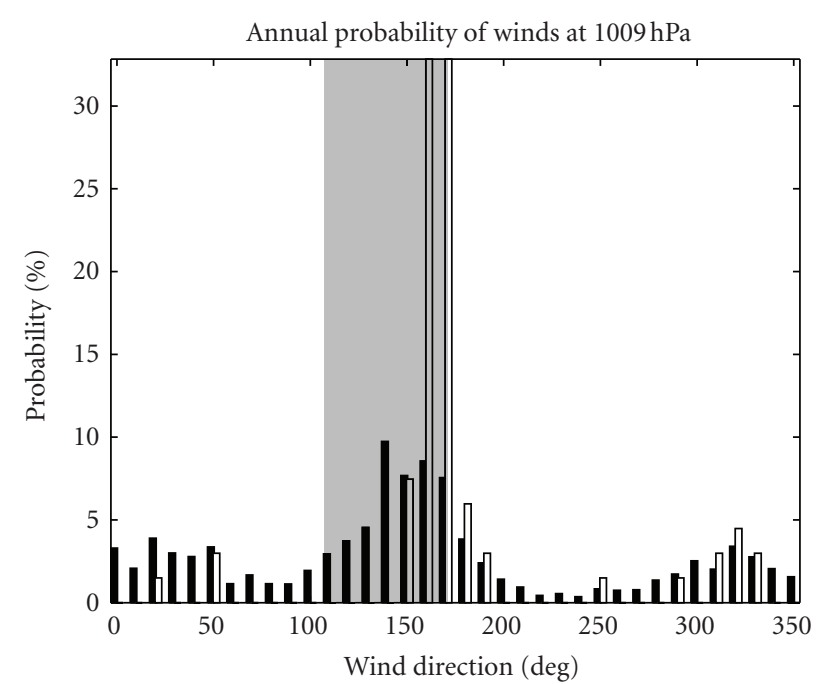

(a)

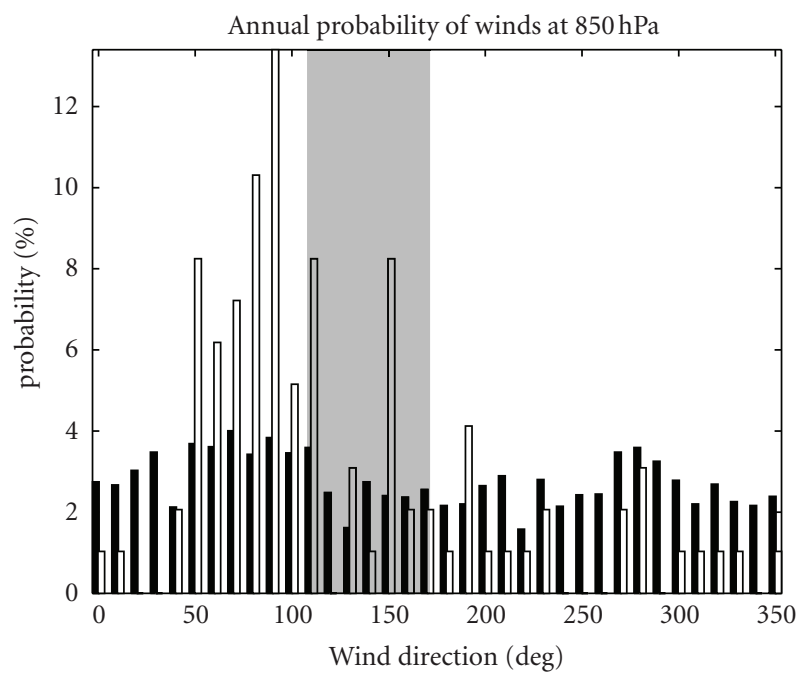

(c)

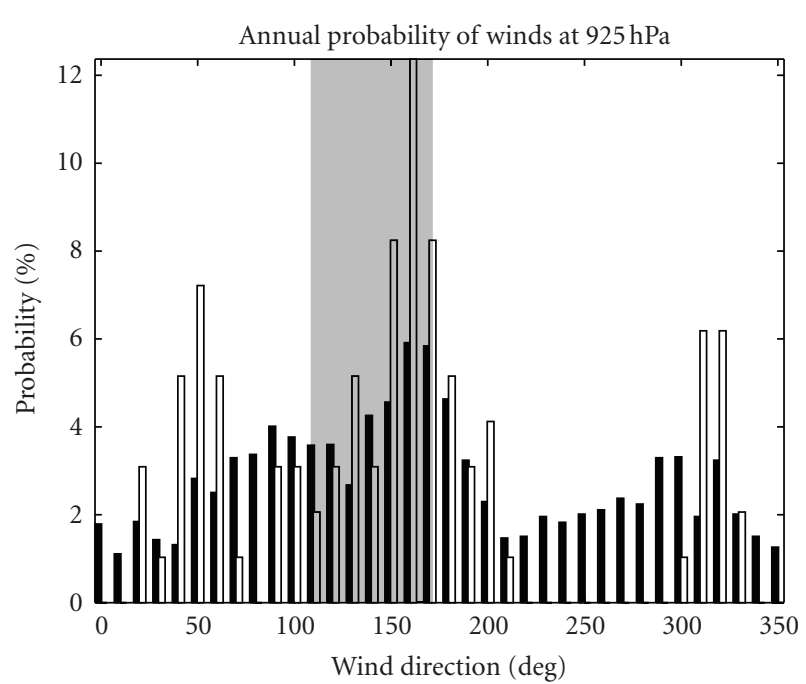

(b)

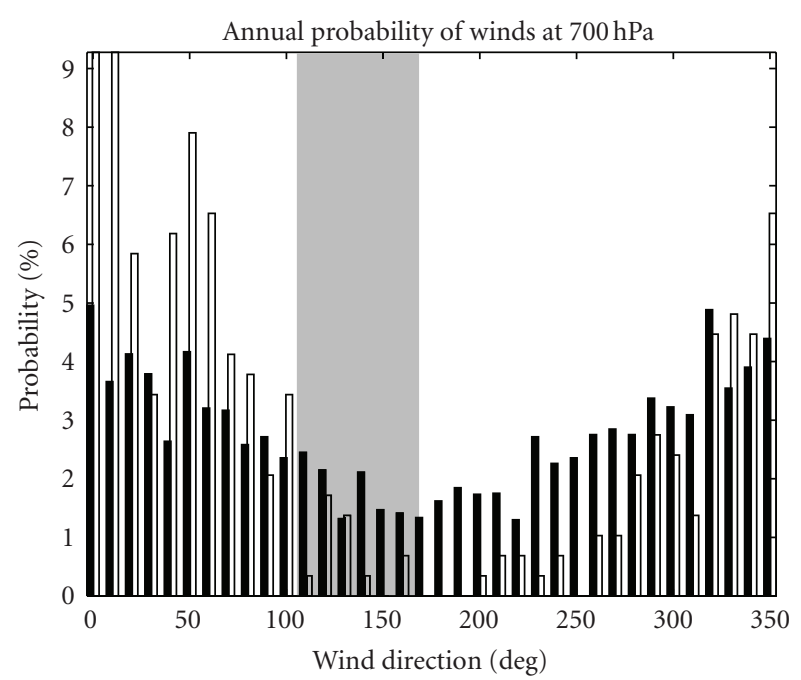

(d)

FIGURE 4: The annual climatological probability of the wind speed to be found within the given range of wind directions. The analysis is based on the IGRA data archive for the Ny-Ålesund stations. The probabilities are shown at four pressure levels: the surface (a), $925 \mathrm{hPa}(\mathrm{b})$, $850 \mathrm{hPa}(\mathrm{c})$, and $700 \mathrm{hPa}(\mathrm{d})$. The black bars correspond to the total probability, and the white bars to the probability of the strongest winds (the wind speed belongs to the top quartile). The gray strips indicate the direction of the valley.

the observations. The probabilities are normalized by the maximum probability found on the plot, which therefore will be equal to 1 . The contour lines of $0.25,0.5,0.75$, and 0.9 of the maximum probability are shown. The composite analysis shows the mean properties of the channeled wind for the entire period of observations since 1974. In addition, we show such an analysis for all May months only and for the period between May 2nd and 13th 2009. The latter period is highlighted due to availability of turbulence and mast measurements for those days. The corresponding meteorological and turbulent characteristics measured by AWS 3 are shown in Figure 7.

The pattern of the temperature in the wind speed and direction phase space is very variable. However, the major part of this variability is associated with rare meteorological events. It is worth to consider only the areas of the phase space, which are under the first contour line. As the katabatic wind is supposed to bring cold temperatures from the glacier, we expect to find a good association between the wind directions in the sector 100-160 degrees, the stronger than average wind speed of 5 to $10 \mathrm{~m} \mathrm{~s}^{-1}$, and the lower temperatures. Although such combination of meteorological parameters could be found on the diagram, it is similarly likely to find the associated high temperatures as well. The high temperatures could indicate the adiabatic air subsidence in the valley due to the mechanical drainage or föhn mechanisms. The pattern of the diagram for May month is generally similar to the pattern on the climatologic diagram. However, May 2009 at the AWS 3 site was different. We found stronger winds and lower temperatures in the valley, which clearly 


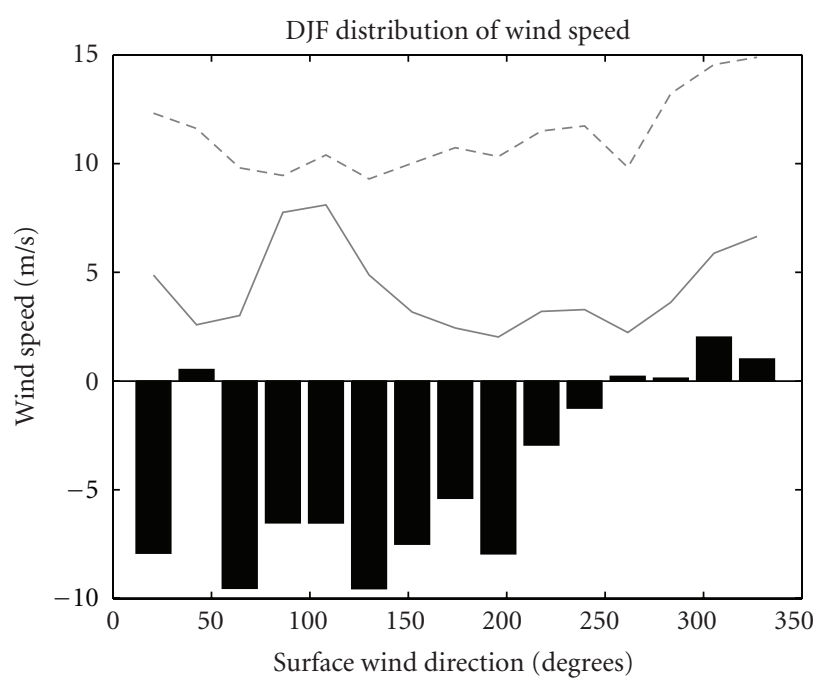

(a)

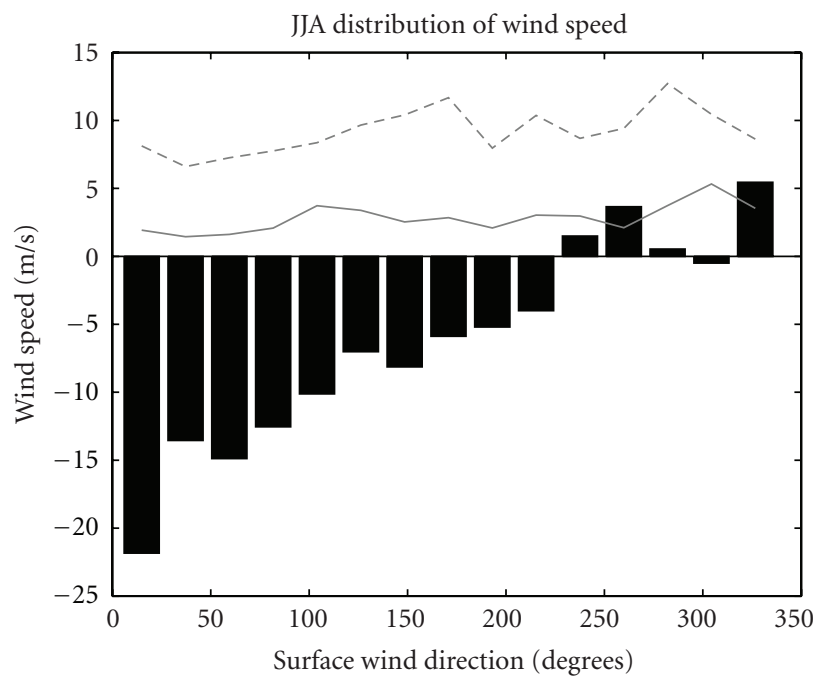

(c)

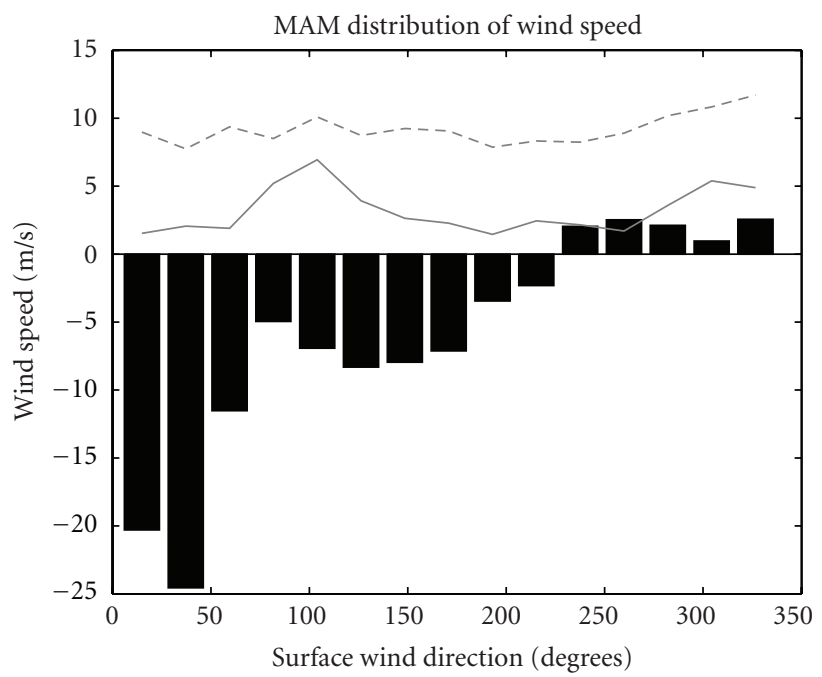

(b)

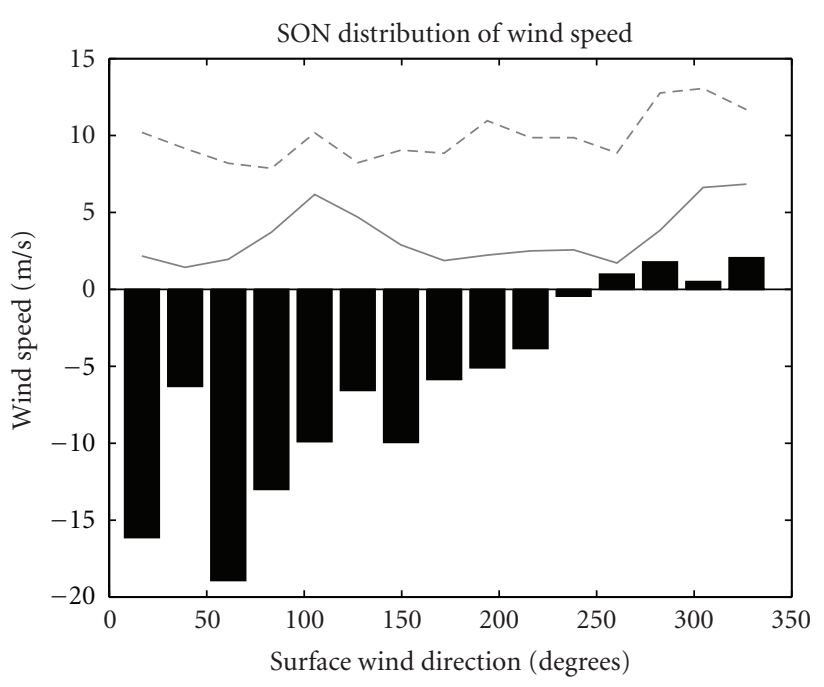

(d)

FIGURE 5: Composite plot of the wind speed at the surface (solid gray line), at the $700 \mathrm{hPa}$ pressure level (dashed gray line), and the angle between wind directions at those surfaces (black bars). The wind speed is given in $\mathrm{m} \mathrm{s}^{-1}$; the angle in degrees $\times 10^{-1}$. The IGRA data analysis for Ny-Ålesund is shown for four seasons: winter (a), spring (b), summer (c), and autumn (d).

indicate the development of the katabatic wind. Figure 7 confirms that the local meteorological conditions at the AWS 3 site and in Ny-Ålesund were often very different with the wind blowing in opposite directions. This observation may explain paradoxical lack of the katabatic winds in the NyÅlesund data. The katabatic wind could be simply too weak to reach this station.

The strongly channeled winds were found in records from other glacier AWSs as well. The highest station (AWS 6) observed the wind directions in the sector of $100^{\circ}$ to $150^{\circ}$ in $20 \%$ (summertime with the minimum in June) to $50 \%$ (springtime with the maximum in March) of cases [11]. The secondary maximum corresponding to the cases with the wind direction of about $300^{\circ}$ could be also identified in the station records. The surface is typically colder than the air above it. At the glacier sites, the temperature difference is usually $10 \mathrm{~K}$ to $20 \mathrm{~K}$ in the winter season and $0 \mathrm{~K}$ to $5 \mathrm{~K}$ in the summer season. By contrast, Oerlemans and Grisogono [18] study of midlatitude glaciers revealed the temperature deficit over the melting ice surface as large as $15 \mathrm{~K}$. As the summertime temperature at Svalbard typically does not exceed $5^{\circ} \mathrm{C}$, such a large temperature deficit is physically impossible. Recall that the asymptotic theory links the temperature deficit with the maximum katabatic wind speed. Thus, smaller temperature deficit on the Svalbard glacier implies much weaker katabatic winds in the valley.

\section{Numerical Simulations of the Wind Patterns Induced by Different Driving Mechanisms}

We established in the previous section, statistical significance, the vertical structure, and the parametrical composition of the winds in the valley. In this section, we will look 


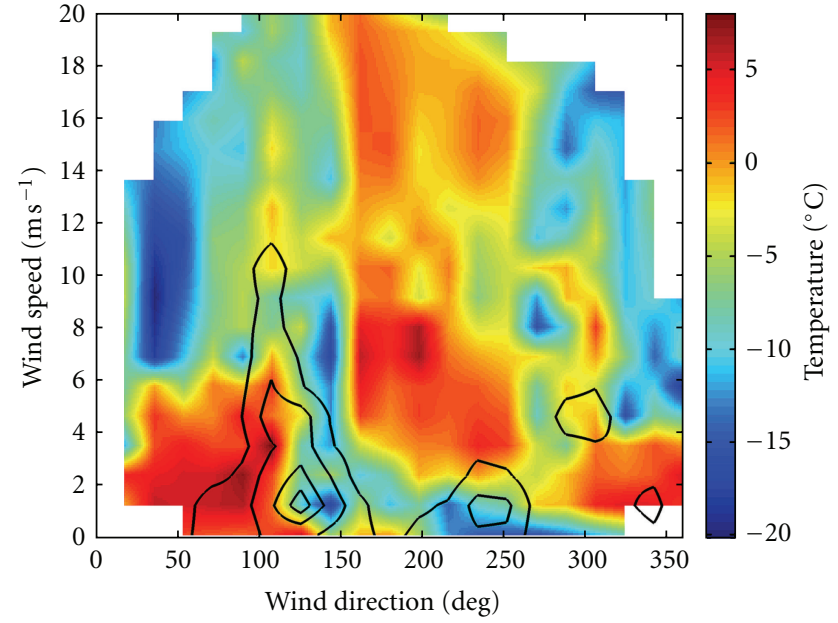

(a)

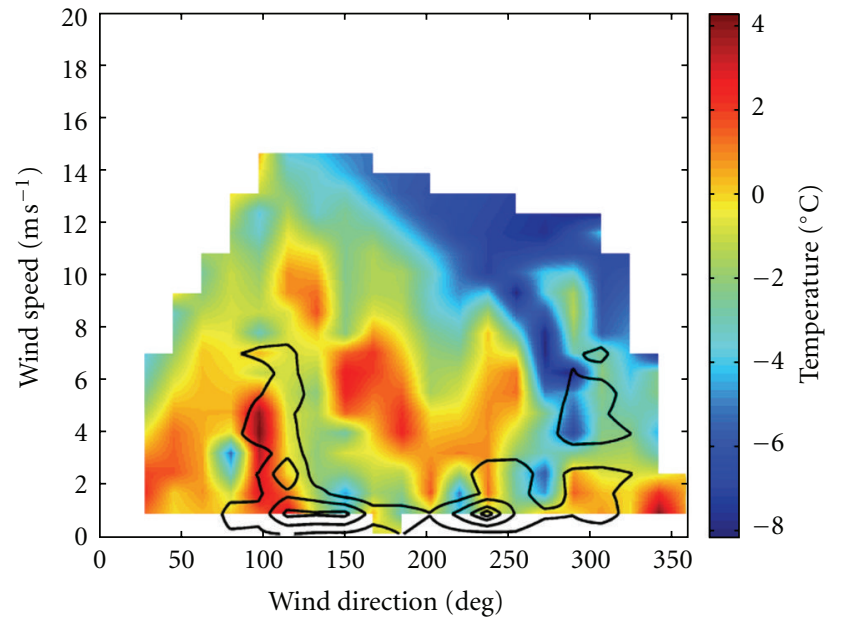

(b)

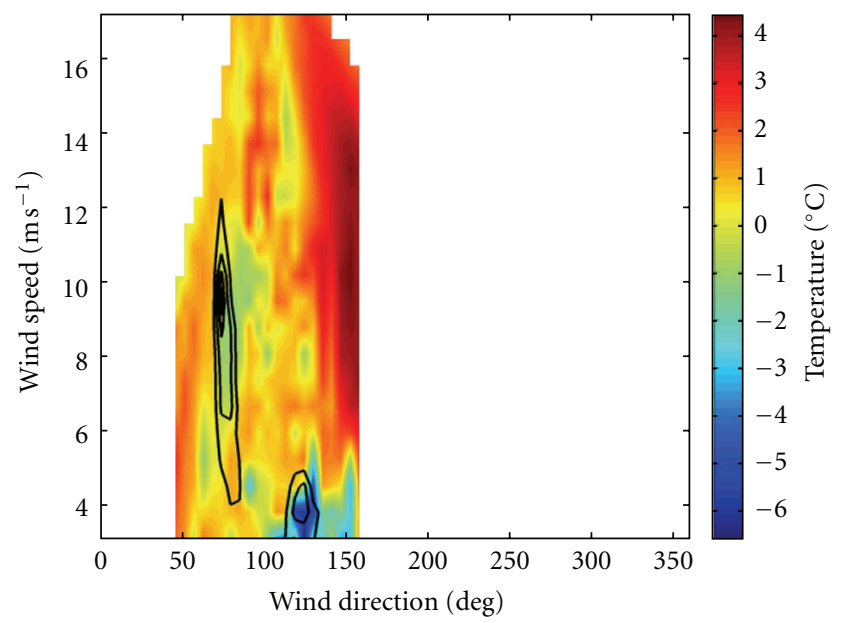

(c)

FIGURE 6: Composite representation of the surface layer meteorological conditions in Ny-Ålesund as observed between 1974 and 2011: (a) during the entire period; (b) during the all May months. (c) The same type of composite representation but for the AWS 3 data during the intensive observation period between May 2nd and 13th 2009. Colors show the mean temperature [ ${ }^{\circ} \mathrm{C}$ ] at $2 \mathrm{~m}$ under the given wind direction and the wind speed. The contours show $0.25,0.5,0.75$, and 0.9 relative probability levels to observe the given combination of the wind speed and direction and the wind speed. Detailed description of the procedure is given in the text.

at the structure of the wind and temperature fields obtained in idealized simulations with a fine resolution turbulence-resolving model. The simulations are aimed to distinct between the wind-temperature patterns generated by each of possible driving mechanisms. This distinction will hopefully improve the attribution of the wind driving mechanisms in the valley complementing previously published case studies where many of those mechanisms were acting simultaneously.

The Parallelized Atmospheric Large-eddy simulation Model (PALM) was utilized. The model was developed at the Institute for Meteorology and Climatology (IMUK) of the Leibniz University of Hannover. The version of PALM used in this study was described in details in Letzel et al. [27]. The model ability to work with stratified flows in complex surface geometry has been described in Castillo et al. [34]. PALM solves the Navier-Stokes and thermo-dynamic equations for the Boussinesq incompressible fluid. PALM also solves the transport equations for a passive scalar or moisture. Further numerical details of PALM could be found in Raasch and Schröter [35] and Castillo et al. [34]. The model simulations were run for the part of the valley, which is shown by the light rectangle in Figure 1. The model resolution was $61 \mathrm{~m}$ in the direction along the valley and $56 \mathrm{~m}$ in the direction across the valley. Despite the fact that the model resolution of our runs is about 20 times finer than the simulations with WRF available to date, this resolution is probably too coarse to resolve the small-scale turbulence in the strongly stratified atmosphere near the surface. In this sense, the PALM simulations still rely on the Smagorinsky turbulent closure to parameterize the turbulent exchange. However, this parameterization deals with the full turbulent stress/diffusivity tensors, which makes it more adequate to the problem in question than the one-dimensional column-wise parameterizations in 


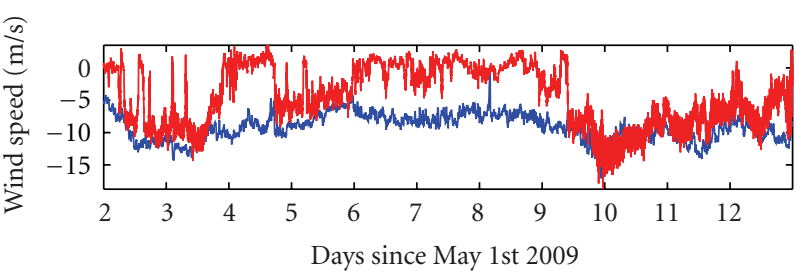

(a)

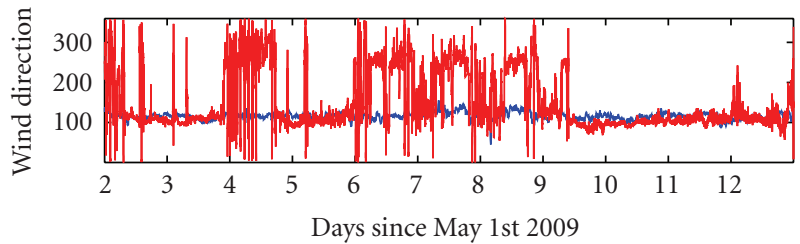

(c)

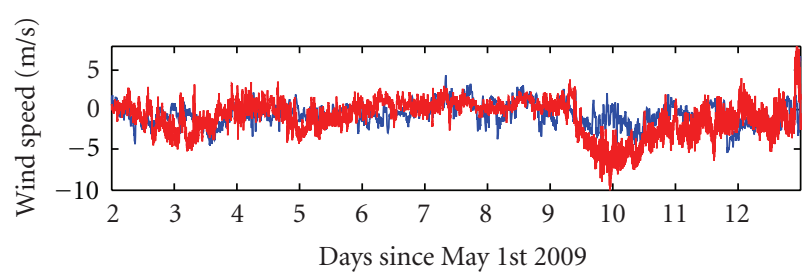

(b)

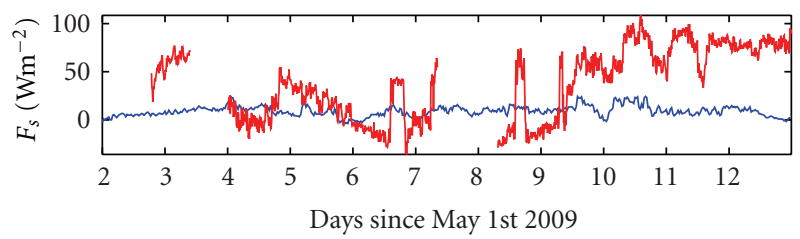

(d)

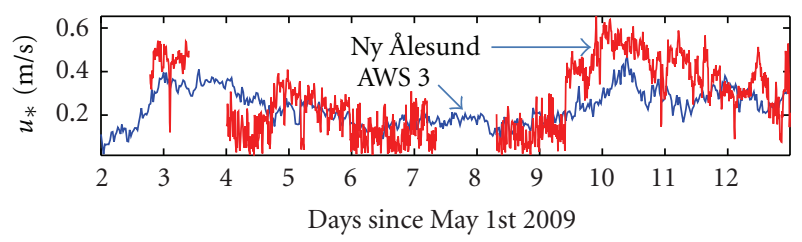

(e)

FIGURE 7: In situ meteorology at the surface layer between May 2nd and 13th 2009: the wind speed projected on the valley axis (a); the wind speed projected on the axis perpendicular to the valley (b); the meteorological wind direction (c); the surface sensible heat flux (d); the surface friction velocity (e). Blue curves: data from AWS 3 on the glacier; red curves: data from the Ny-Ålesund station.

the WRF model. Although the turbulent processes governed by the stable stratification of the surface atmosphere are not resolved, the simulations are still turbulence-resolving as the large-scale turbulence generated by topographical features is resolved. Thus, the model achieves a qualitative shift from the parameterized to resolved turbulence for a part of the turbulent spectra on scales larger than about $100 \mathrm{~m}$. In this sense, PALM resolves the energy containing part of the turbulence spectrum [36]. To use this advantageous feature, turbulenceresolving simulations have been already applied in several katabatic wind studies (e.g., $[37,38]$ ).

The model mesh in this study was chosen to be 2048 by 128 grid point. The selected domain occupied only 512 (along the valley) by 112 (across the valley) grid points within this mesh. The rest of the mesh is used to create periodic boundary conditions, which are at sufficient distance from the selected domain to minimize the effect of the flow recycling. This resolution is to be compared with the resolution in the WRF simulations where just $2-5$ grid points were placed across the valley. The vertical resolution of the simulations was $10 \mathrm{~m}$ in the lowest $500 \mathrm{~m}$ of the domain and stretched to $60 \mathrm{~m}$ at the domain top. The total number of the vertical levels was 128 . The initial potential temperature gradient was set to $6.3 \mathrm{~K} \mathrm{~km}^{-1}$ to be consistent with the climate data. It is important to bear in mind that the PALM model is incompressible and, therefore, calculates the potential temperature. The potential temperature, which is referred just as temperature, does not change in the adiabatic processes such as up- and down-ward motions. However, the initial potential temperature gradient implies that the higher potential temperature can be entrained into the lower layers from the upper part of the domain. This entrainment will be clearly seen in the simulation results. Unresolved surface roughness was taken $0.01 \mathrm{~m}$. Table 2 lists the other initial conditions of the runs.

To run the simulations, two sets of initial conditions were used. One set of runs had no background wind. Another set of runs was driven with the constant background wind of $U=$ $10 \mathrm{~m} \mathrm{~s}^{-1}$ and $V=0 \mathrm{~m} \mathrm{~s}^{-1}$ where $U$ and $V$ are the velocity components along and across the valley with the positive sign corresponding to the wind from the fjord mouth towards the glacier. The surface kinematic heat flux over the open water area in the domain (the blue area in Figure 1) was set to $0.1 \mathrm{~K} \mathrm{~m} \mathrm{~s}^{-1}$, which roughly corresponds to the upward heat flux of $100 \mathrm{~W} \mathrm{~m}^{-2}$. The flux over the land surface was set either to $-0.02 \mathrm{~K} \mathrm{~m} \mathrm{~s}^{-1}$ or to $0.0 \mathrm{~K} \mathrm{~m} \mathrm{~s}^{-1}$. The model was integrated for 6 model hours. Due to very large amount of data produced by the model integration, only a limited sampling at selected vertical levels and along-valley slices was applied. The data were sampled every $30 \mathrm{~min}$. Each run was initiated with slightly perturbed laminar flow. Therefore, runs undergo a spin-up period. The run post-processing revealed that the flow in the domain of interest is nearly statistically steady state already after 3 hours of simulations. Nevertheless, we used for this study the averaged meteorological fields sampled between hours 5 and 6 of simulations. As the flow in the valley is strongly channeled, this study is limited only to the analysis of the averaged circulation in the vertical plane aligned with the valley major axis. The data were averaged over 4 instant samplings and from 
TABLE 2: The initial and boundary conditions of the numerical experiments with the PALM code.

\begin{tabular}{lccccc}
\hline Run & Symbol & $\begin{array}{c}\text { Initial wind }(U, V) \\
{\left[\mathrm{m} \mathrm{s}^{-1}\right]}\end{array}$ & $\begin{array}{c}\text { Surface temperature flux } \\
\text { (open water), }\left[\mathrm{K} \mathrm{m} \mathrm{s}^{-1}\right]\end{array}$ & $\begin{array}{c}\text { Surface temperature flux } \\
\text { (land and ice), }\left[\mathrm{K} \mathrm{m} \mathrm{s}^{-1}\right]\end{array}$ & Relief \\
\hline R0SF & $\bullet$ & $(0.0,0.0)$ & 0.1 & -0.02 & Yes \\
R0FF & $\bigcirc$ & $(0.0,0.0)$ & 0.1 & -0.02 & No \\
R10SF & $\mathbf{D}$ & $(10.0,0.0)$ & 0.1 & -0.02 & Yes \\
R10FF & $\square$ & $(10.0,0.0)$ & 0.1 & -0.02 & No \\
R10S0 & $\boldsymbol{( \Delta}$ & $(10.0,0.0)$ & 0.1 & 0.0 & Yes \\
R10F0 & $\triangle$ & $(10.0,0.0)$ & 0.1 & 0.0 & No \\
R10S00 & $\nabla$ & $(10.0,0.0)$ & 0.0 & 0.0 & Yes \\
\hline
\end{tabular}

three vertical slices along the valley. The slices are located at the valley central line and at the distance of about $2 \mathrm{~km}$ from the central line on each side of it.

The performed runs allow comparison of the mean wind-temperature patterns induced in the valley separately for three driving mechanisms: the mechanical forcing and drainage, the thermally forced land-sea breeze circulation, and the katabatic wind. Figure 8 shows wind and temperature anomalies obtained in four runs: R0SF and R0FF- two runs without the external mechanical forcing; and R10SF and R10S0 - two runs with the strong external mechanical forcing pushing the air into the valley from open water. Other performed runs will not be shown here due to limited journal space. The temperature anomaly is defined as the difference between the temperature at given location and the temperature averaged over the open water part of the domain for the same height above the sea level. The obtained temperature anomalies were rescaled to be within the range $[-1 \mathrm{~K}$; $-10 \mathrm{~K}]$. This procedure makes the runs directly comparable to each other.

The run R0SF (Figure 8(a)) simulates the atmospheric circulation driven by the differential cooling of the realistic valley surface. Thus, the circulation in the ROSF is driven by the combined effect of the katabatic wind (due to the presence of the cooled slope) and the breeze (due to the horizontal thermal gradient between open water and the land in the domain). In the run R0FF (Figure 8(b)), however, the katabatic wind mechanism is absent as the simulations were performed with the flat surface domain. The run R0FF develops a typical sea breeze circulation pattern with the strong low-level flow directed from cold (land) to warm (open water) parts of the valley and the weak compensating highlevel flow in the opposite direction. The maximum low-level wind speed reaches $-8 \mathrm{~m} \mathrm{~s}^{-1}$ near the surface at the edge of open water. Arrows reveal significant vertical velocity at the sea breeze front. As it has been noted previously, the entrainment of the potentially warmer air from the upper levels in the down-draft branch of the circulation is clearly seen in the right part of the plots. The surface temperature over the land is about $5 \mathrm{~K}$ colder in this simulation than the open water temperature. Here, we probably see the model failure to produce turbulence in the stably stratified surface layer as the vertical temperature gradient at the surface is too sharp. The thickness of the layer affected by the surface cooling is about $100 \mathrm{~m}$. But the circulation reverts at much higher elevation of about $700 \mathrm{~m}$. The considered details of the breeze circulation are in good correspondence to the theoretical expectations $[39,40]$.

The circulation in the run R0SF (Figure 8(a)) closely resembles the breeze circulation. The principal properties of the temperature and wind fields are very similar to the properties found in the ROFF. However, the circulation is intensified. The maximum low-level wind speed reaches $-11 \mathrm{~m} \mathrm{~s}^{-1}$ near the surface at the open water edge. The nonflat surface generates significant turbulence, which mixes the temperature and disturbs the breeze circulation. The layer of cooled air is significantly thicker towards the end of the slope reaching $200 \mathrm{~m}$ to $300 \mathrm{~m}$. Simultaneously the entrainment of higher potential temperature in the down-ward branch of the circulation has significantly increased. At the same time, the circulation reverts at about the same $700 \mathrm{~m}$ height. This comparison suggests that the effect of the slope does not play a leading role in driving of the circulation. The effect is relatively minor and only assists and, to some degree, amplifies the breeze circulation. The katabatic wind mechanism affects at the most the lowermost $50 \mathrm{~m}$ in the domain. Figure 9(a) compares the wind speed directly as it has been recalculated to obtain the heights above the inclined surface. In the lower layer $(0 \mathrm{~m}$ to $50 \mathrm{~m})$, the katabatic wind accelerates the flow between $2 \mathrm{~km}$ and $12 \mathrm{~km}$ and between $15 \mathrm{~km}$ and $25 \mathrm{~km}$ from the mouth of the fjord. At the distances between $12 \mathrm{~km}$ and $15 \mathrm{~km}$, one can find some sort of obstacles (cliffs or islets) in the valley, which force the flow to move upward and above the $50 \mathrm{~m}$ layer. At the same time, the mean wind speed in the thicker $500 \mathrm{~m}$ layer is only marginally larger than the wind speed in the flat surface run ROFF. Thus, the acceleration is significant but seen only in the lowermost $100 \mathrm{~m}$ or less. The additional acceleration by the katabatic wind pushes the breeze front by just a few kilometers. This is consistent with the qualitative experience of observers that the glacier winds do not penetrate far over the open water part of the fjord.

Our statistical analysis has demonstrated that the mean background wind above the valley is about $10 \mathrm{~m} \mathrm{~s}^{-1}$. The background wind can significantly modify circulations in the valley as it imposes additional mechanical forcing $[14,26]$. According to Doran [14], the mechanical driving creates higher pressure in the valley. It causes air drainage along the slope in the lower layers, sometimes in the direction opposite to the background wind. To clarify the effect, five runs with the background wind were performed (see Table 2). The runs 


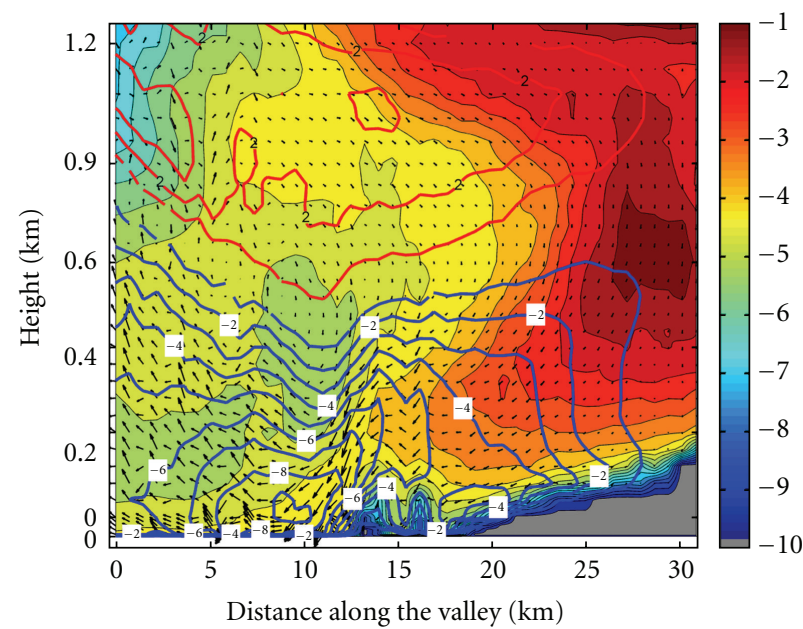

(a) R0SF

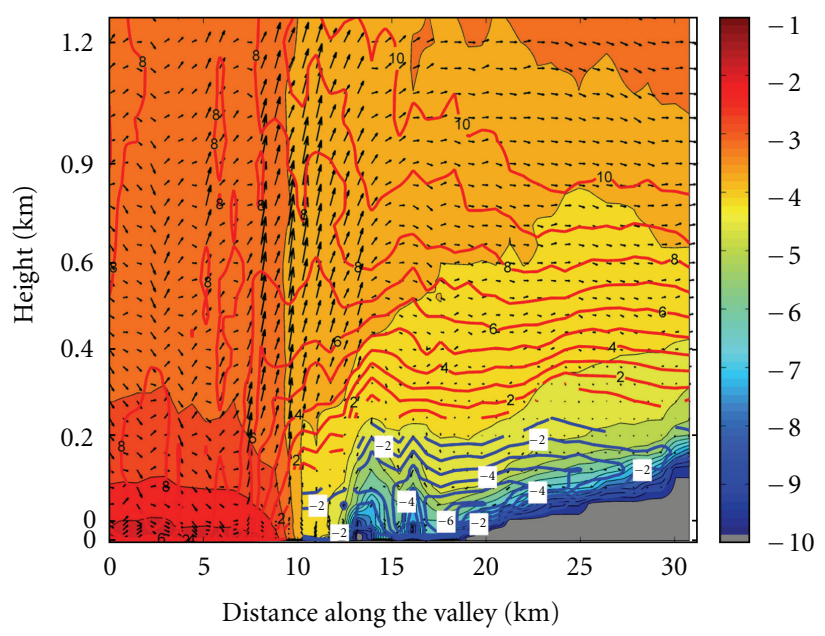

(c) R10SF

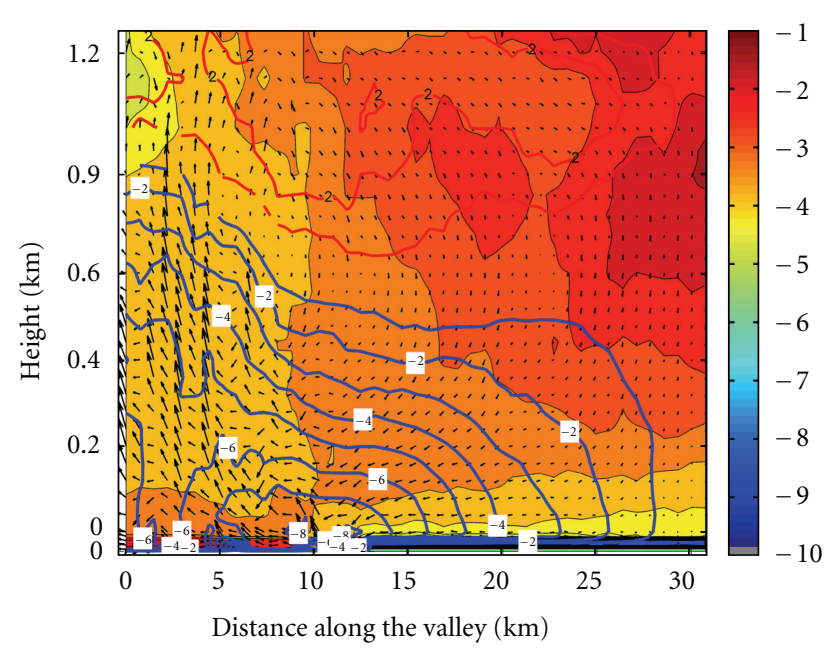

(b) ROFF

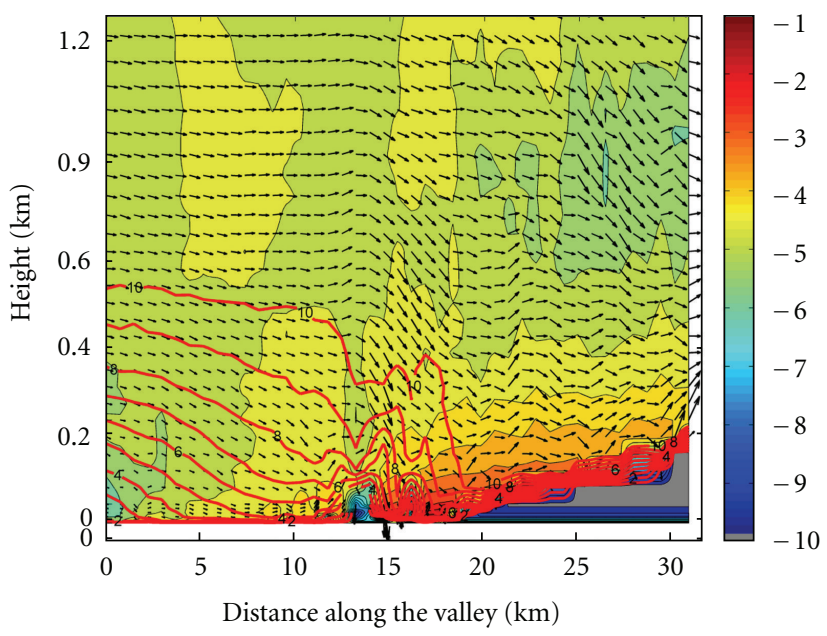

(d) R10S00

FIGURE 8: The averaged circulation in the vertical plane with orientation along the central axis of the valley. The velocity vectors represent the horizontal (along the valley) and vertical component of the wind. The wind speed $\left(\mathrm{m} \mathrm{s}^{-1}\right)$ is shown by isolines. Winds down the valley are indicated with blue isolines; winds in the opposite direction, with red isolines. Temperature anomalies (see the text for details) are shown through color. The gray shading shows the surface elevation. Four runs are shown: (a) R0SF: the thermally driven breeze circulation over the realistic relief of the surface (b) R0FF: the thermally driven breeze circulation over flat but differentially cooled surface; (c) R10SF: the circulation over the cooled surface in presence of the strong westerly background wind; (b) R10S00: the circulation over the surface with no additional cooling in presence of the strong westerly background wind.

with the realistic topography (with and without land cooling) are shown in Figures 8(c) and 8(d). The runs R10SF and R10S00 have the background wind of $10 \mathrm{~m} \mathrm{~s}^{-1}$ in the valley direction. Comparison between runs R0SF (Figure 8(a)) and R10SF (Figure 8(c)) shows that the background on-slope wind strongly suppresses but not eliminates the surface layer with the down-slope winds. The breeze front becomes very sharp in this case. The upward motions at the front are strong (up to $1 \mathrm{~m} \mathrm{~s}^{-1}$ ). The run R10S00 (Figure 8(d)) reveals that the down-slope winds does not develop in absence of the katabatic wind and the breeze mechanisms under the typical forcing conditions. Thus, the presence of the surface layer cooling or the horizontal temperature gradient is needed to maintain the surface wind counter flow. Figures $9(\mathrm{~b})$ and 9(c) reveal that the background wind shifts the breeze front and makes the additional effect of the katabatic wind mechanism insignificant.

The layer with such winds is also much thinner under the conditions with the background wind. In the run R10SF, thickness of this layer was just $150 \mathrm{~m}$ to $200 \mathrm{~m}$. Detailed study of the effects of the background wind speed and direction on circulations in a valley has been published by Doran [14]. Figure 10 compares the results of Doran's simulations with the present simulations. The present simulations are in good agreement with the overall linear regression on the plot. This dependence needs more studies. In particular, it would be 


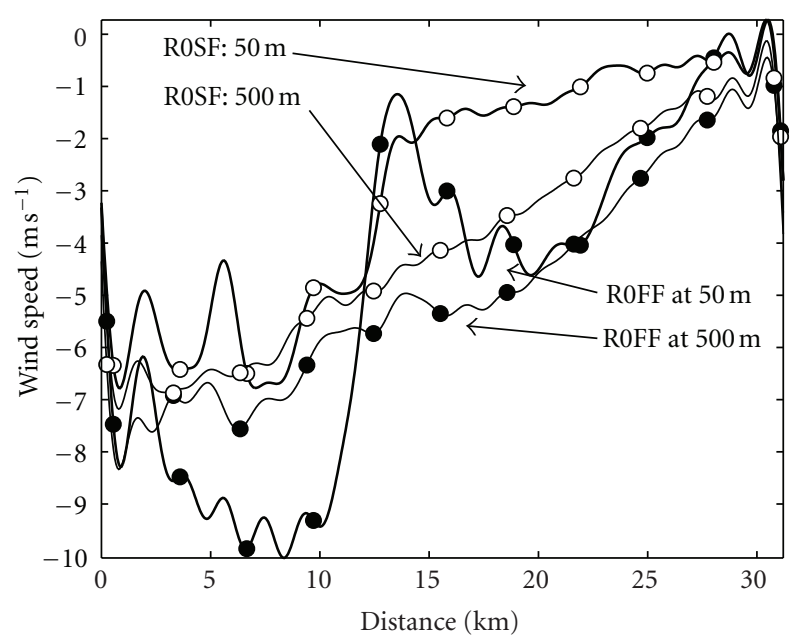

(a)

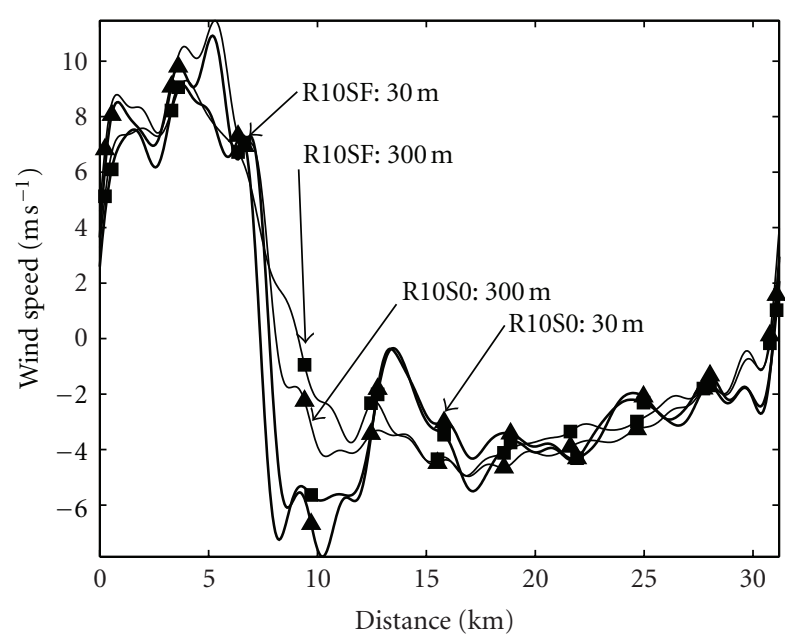

(b)

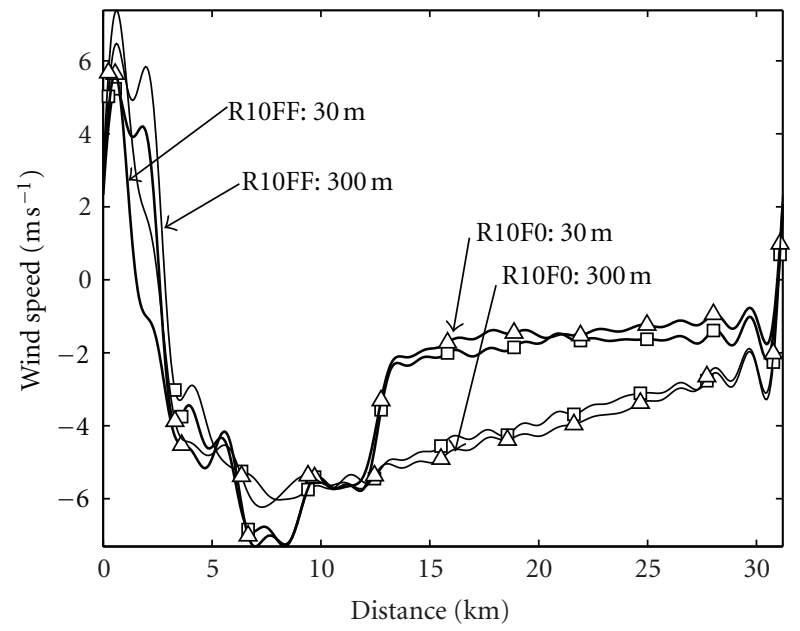

(c)

FIGURE 9: The averaged wind speed in the lower layer (thick lines) and in a thicker layer (thin lane) in the domain. The heights were recalculated relative to the inclined surface. (a) The runs R0SF (black circles) and R0FF (white circles); (b) the runs R10SF (black squares) and R10S0 (black triangles); (c) the runs R10FF (white squares) and R10F0 (white triangles).

interesting to find the combination of the wind speed and direction, the surface cooling rate, and the slope angle at which down-slope flows appear.

\section{Attribution of Wind Driving Mechanisms to the Observed Wind Patterns}

Strong and persistent channeled wind has been reported in several previous analyses of the surface layer observations in the valley. More detailed but short-term studies of the phenomenon during field observational campaigns (e.g., in ARTIST; [7]) disclosed that the thickness of the layer with persistent winds was just of $300 \mathrm{~m}$ to $500 \mathrm{~m}$. The wind direction changed significantly above this layer. In this study, we completed those findings with the statistical analysis of the long-term radiosounding data archive IGRA. The previous observations were corroborated and extended. In particular, we presented the climatological analysis of the vertical structure of the winds in the valley. We also linked this structure with the structure of temperature anomalies. We demonstrated that the channeled winds are typical for both winter and summer seasons. The thickness of the surface layer winds reveals significant seasonal variations. In the summer season, the layer is thinner. Although we did not have high-resolution vertical profiles for analysis, the wind rotation suggests that $500 \mathrm{~m}$ depth might be a reasonable estimation of the layer thickness. The winter season is characterized with thicker layer of about $1000 \mathrm{~m}$ depth, which is comparable with the height of the surrounding mountains.

The statistical analysis of the wind vertical structure has revealed that the surface winds frequently blow in the direction opposite to the direction of the geostrophic winds at higher atmospheric levels. This feature suggests an action of a specific driving mechanism, which reverts the background atmospheric winds. A number of studies refer to the katabatic wind mechanism. Indeed, some features of the surface 


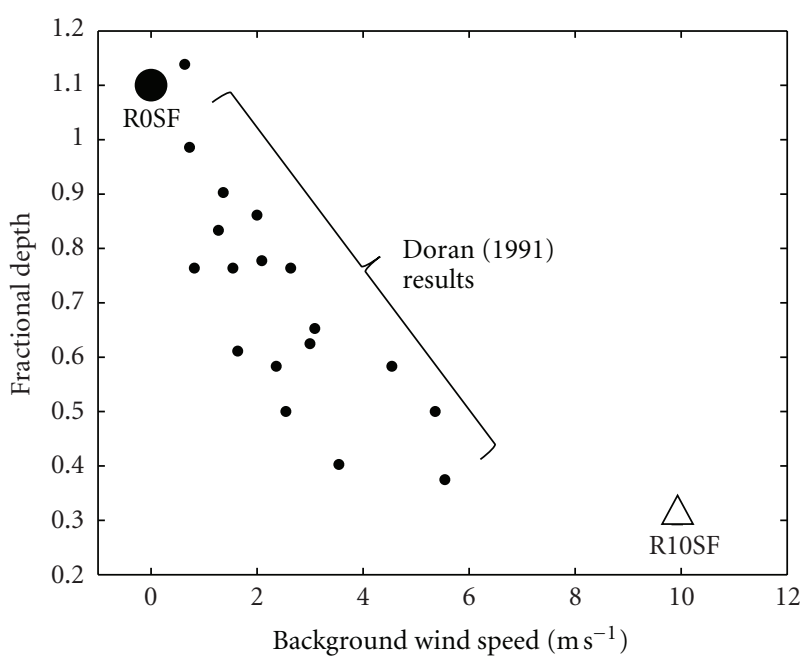

FIgURE 10: The thickness of the surface layer with winds directed to down slope in the valley. The thickness is normalized by valley depth. The small black dots represent data from Doran [14]. The present runs R0SF (black dot) and R10SF (triangle) are given by large symbols.

layer winds in the valley resemble the typical katabatic wind features. However, the channeled wind layer was found too deep as compared to the theoretical predictions $[16,17,21]$. The theories of the katabatic wind are of cause strongly simplified and linearized to be treated analytically. They parameterize suppression of the turbulence in the stably stratified layer and, therefore, the reduced transport of momentum from the accelerating surface layer air to higher layers of the atmosphere. Recent turbulence-resolving simulations by Axelsen and van Dop [38] and Largeron et al. [41] addressed the turbulence structure in the katabatic wind without simplifications imposed on the turbulence profile. In particular, Largeron et al. [41] found the thickness of the katabatic wind layer to be not deeper than $50 \mathrm{~m}$. This is one order of magnitude less than the thickness found in our statistical analysis of the wind profile climatology. The simulations, however, were performed for a valley with featureless, smooth slopes.

The heterogeneity of the realistic relief can create additional turbulence due to the form drag of the resolved-scale obstacles (small valleys and islets in the fjord). Therefore, new turbulence-resolving simulations with the PALM code have been performed for this study with realistic topography taken from the ASTER digital elevation model. These simulations were not designed to mimic any observed meteorological situation because such a situation is unavoidably complicated by a superposition of different driving mechanisms and large-scale synoptic tendencies. Instead, we designed a set of simulations to single out particular driving mechanisms and to study the wind structure patterns corresponding to them.

Unfortunately, the pure katabatic wind mechanism can be simulated only in a model with infinite inclined slope. Such simulations cannot be performed with the realistic relief in the model domain. Therefore, we studied the effect of the katabatic wind driving mechanism through intercomparisons of simulations with and without the relief. The simulations demonstrated that the major driving mechanism should be attributed to the land-sea breeze circulation driven by the horizontal temperature difference between the open water part of the fjord and the glacier. The katabatic wind mechanism strengthens this circulation significantly only in the lower $50 \mathrm{~m}-100 \mathrm{~m}$. This circulation seems to be necessary to produce the near surface wind reversal in the meteorological situations with significant background winds. In turn, the background westerly winds are needed to produce the thickness of the surface layer-channeled winds of the order of observed $300 \mathrm{~m}$. In the simulations with no background winds, the thickness of this layer was obtained deeper by a factor of two.

It is certain that our simulations could not explain all details of the observed climatological wind structure. Our simulations reveal that the breeze front moves only $5 \mathrm{~km}$ to $10 \mathrm{~km}$ off the oblation glacier edge. It is too short distance to explain persistent winds with vertical reversal of directions found in Ny-Ålesund data. As found by Skeie and Grønås [6], Sandvik and Furevik [2], Livik [12], and Kilpeläinen et al. [13], there are also regional circulations at larger scales, which can significantly influence the wind structure in the valley. In particular, the work of Livik [12] suggests that the simulations must also include the area of the adjacent Kronebreen glacier to be able to reproduce the circulations toward the mouth of the valley.

Finally, it has to be mentioned that the fjord may have own microclimate, which is different from the climate of the marine part of the region. Unfortunately, there are no longterm records for the latter part to estimate this difference. Nevertheless, close analogies can be drawn between the wind climate and its attribution to the wind driving mechanisms found in the statistical analysis of the northern Norwegian fjords by Nawri and Harstveit [26] and the wind climate and its attribution reported in this study for the Arctic fjord. Simulations by Kilpeläinen et al. [13] suggest that the difference in temperature could be as large as $+3 \mathrm{~K}$. The development of the breeze circulation in the valley can have such warming effect through frequent entrainment and recirculation of the warmer marine air in the valley. Attributing larger role in the Arctic fjord microclimate to the breeze circulation, we emphasize the difference between the Arctic and midlatitude mounting glacier conditions. As it has been described in Oerlemans and Grisogono [18], the midlatitude glaciers have stronger surface cooling due to higher ambient air temperature. Correspondingly, the large surface temperature deficit generates stronger katabatic winds. The high-latitude glaciers in Svalbard have typically much smaller deficit due to lower air temperatures, and therefore, the katabatic winds are not the primary driving mechanism of the circulation in the valley.

\section{Acknowledgments}

The authors thank for the support of the Norwegian Research Council bilateral collaboration projects: NERSCIAP 196174/S30: The Atmospheric Boundary Layer Structure and Surface-Atmosphere Exchange in the Svalbard Area; PAACSIZ 178908/S30: Planetary Boundary Layer Feedbacks 
Affecting the Polar Amplification of Arctic Climate Change in Seasonal Ice Zone; NERSC-IARC 196178/S30: Detailed Studies of the Bjerknes Compensation Mechanism. The work has been also supported by the grant of the Government of the Russian Federation designed to support scientific research projects implemented under the supervision of leading scientists at Russian institutions of higher learning (project code 11.G34.31.0048) and by the European Research Area Advanced Research Grant no. 227915 PBL-PMES.

\section{References}

[1] F. Geyer, I. Fer, and L. H. Smedsrud, "Structure and forcing of the overflow at the Storfjorden sill and its connection to the Arctic coastal polynya in Storfjorden," Ocean Science, vol. 6, no. 1, pp. 401-411, 2010.

[2] A. D. Sandvik and B. R. Furevik, "Case study of a coastal jet at Spitsbergen-comparison of SAR- and model-estimated wind," Monthly Weather Review, vol. 130, no. 4, pp. 10401051, 2002.

[3] I. Hanssen-Bauer, M. K. Solas, and E. L. Stefensen, "The climate of Spitsbergen," Den Norske Meteorologiske Institutt report, Oslo, Norway, DMNI, 39/90 KLIMA, 1990.

[4] E. J. Førland, I. Hansen-Bauer, and P. Ø. Nordli, "Climate statistics and long-term series of temperature and precipitation at Svalbard and Jan Mayen," Den Norske Meteorologiske Institutt report, Oslo, Norway, DNMI Report 21/97 KLIMA, 1997.

[5] J. Hartmann, F. Albers, S. Argentini et al., "Arctic radiation and turbulence interaction study (ARTIST)," Report on Polar Research 305/1999, 81 pp., 1999.

[6] P. Skeie and S. Grønås, "Strongly stratified easterly flows across Spitsbergen," Tellus A, vol. 52, no. 5, pp. 473-486, 2000.

[7] H. J. Beine, S. Argentini, A. Maurizi, G. Mastrantonio, and A. Viola, "The local wind field at Ny-Ålesund and the Zeppelin mountain at svalbard," Meteorology and Atmospheric Physics, vol. 78, no. 1-2, pp. 107-113, 2001.

[8] H. Svendsen, A. Beszczynska-Møller, J. O. Hagen et al., "The physical environment of Kongsfjorden-Krossfjorden, and Arctic fjord system in Svalbard," Polar Research, vol. 21, no. 1, pp. 133-166, 2002.

[9] S. Argentini, A. P. Viola, G. Mastrantonio, A. Maurizi, T. Georgiadis, and M. Nardino, "Characteristics of the boundary layer at Ny-Ålesund in the Arctic during the ARTIST field experiment," Annali di Geofisica, vol. 46, no. 2, pp. 185-196, 2003.

[10] S. Erath, Simulation of the mass and energy balance at Kongsvegen 2001-2003, M.S. thesis, University Innsbruck, 2005.

[11] Th. Krismer, Local and Spatial Mass Balance Modelling on an Arctic Glacier Kongsvegen, Spitzbergen, University of Innsbruck, 2009.

[12] G. Livik, An Observational and Numerical Study of Local Winds in Kongsfjorden, Spitsbergen, M.S. thesis, Geophysical Institute, University of Bergen, 2011.

[13] T. Kilpeläinen, T. Vihma, and H. Ólafsson, "Modelling of spatial variability and topographic effects over arctic fjords in svalbard," Tellus A, vol. 63, no. 2, pp. 223-237, 2011.

[14] J. C. Doran, "The effects of ambient winds on valley drainage flows," Boundary-Layer Meteorology, vol. 55, no. 1-2, pp. 177$189,1991$.

[15] L. Prandtl, Fuhrer durch die Stroemungslehre, Vieweg, Braunschweig, Germany, 1949.
[16] L. N. Gutman, "On the theory of the katabatic slope wind," Tellus, Series A, vol. 35, no. 3, pp. 213-218, 1983.

[17] A. M. J. Davis and R. T. Mcnider, "The development of antarctic katabatic winds and implications for the coastal ocean," Journal of the Atmospheric Sciences, vol. 54, no. 9, pp. 12481261, 1997.

[18] J. Oerlemans and B. Grisogono, "Glacier winds and parameterisation of the related surface heat fluxes," Tellus A, vol. 54, no. 5, pp. 440-452, 2002.

[19] E. J. Klok, M. Nolan, and M. R. Van Den Broeke, "Analysis od meteorological data and the surface energy balance of McCall Glacier, Alaska, USA," Journal of Glaciology, vol. 51, no. 174, pp. 451-461, 2005.

[20] B. Grisogono and J. Oerlemans, "A theory for the estimation of surface fluxes in simple katabatic flows," Quarterly Journal of the Royal Meteorological Society, vol. 127, no. 578, pp. 27252739, 2001.

[21] L. K. Ingel, "Toward a nonlinear theory of katabatic winds," Fluid Dynamics, vol. 46, no. 4, pp. 505-513, 2011.

[22] D. E. England and R. T. McNider, "Concerning the limiting behavior of time-dependent slope winds," Journal of the Atmospheric Sciences, vol. 50, no. 11, pp. 1610-1613, 1993.

[23] R. G. Barry, Mountain Weather and Climate, Cambridge University Press, Cambridge, UK, 2008.

[24] C. D. Whiteman and J. C. Doran, "The relationship between overlying synoptic-scale flows and winds within a valley," Journal of Applied Meteorology, vol. 32, no. 11, pp. 1669-1682, 1993.

[25] M. G. Cogliati and N. A. Mazzeo, "Air flow analysis in the upper Río Negro Valley (Argentina)," Atmospheric Research, vol. 80, no. 4, pp. 263-279, 2006.

[26] N. Nawri and K. Harstveit, "Variability of surface wind directions over Finnmark, Norway, and coupling to the larger-scale atmospheric circulation," Theoretical and Applied Climatology, vol. 107, no. 1-2, pp. 15-33, 2012.

[27] M. O. Letzel, M. Krane, and S. Raasch, "High resolution urban large-eddy simulation studies from street canyon to neighbourhood scale," Atmospheric Environment, vol. 42, no. 38, pp. 8770-8784, 2008.

[28] I. Durre, R. S. Vose, and D. B. Wuertz, "Overview of the integrated global radiosonde archive," Journal of Climate, vol. 19 , no. 1, pp. 53-68, 2006.

[29] I. Esau and S. Sorokina, "Climatology of the arctic planetary boundary layer," in Atmospheric Turbulence, Meteorological Modeling and Aerodynamics, P. R. Lang and F. S. Lombargo, Eds., pp. 3-58, Nova Science Publishers, 2010.

[30] S. Sorokina and I. Esau, "Meridianal energy flux in the Arctic obtained from data of the IGRA radio sounding archive," Izvestiya, Atmospheric and Oceanic Physics, vol. 47, no. 5, pp. 572-583, 2011.

[31] S. S. Zilitinkevich and I. N. Esau, "Similarity theory and calculation of turbulent fluxes at the surface for the stably stratified atmospheric boundary layer," Boundary-Layer Meteorology, vol. 125, no. 2, pp. 193-205, 2007.

[32] S. S. Zilitinkevich, T. Elperin, N. Kleeorin et al., "Turbulence energetics in stably stratified geophysical flows: strong and weak mixing regimes," Quarterly Journal of the Royal Meteorological Society, vol. 134, no. 633, pp. 793-799, 2008.

[33] B. S. Gera, S. Argentini, G. Mastrantonio, A. Viola, and A. Weill, "Characteristics of the boundary layer thermal structure at a coastal region of Adelie Land, East Antarctica," Antarctic Science, vol. 10, no. 1, pp. 89-98, 1998. 
[34] M. C. L. Castillo, M. Kanda, and M. O. Letzel, "Heat ventilation efficiency of urban surfaces using large-eddy simulation," Annual Journal of Hydraulic Engineering, vol. 53, pp. 175-180, 2009.

[35] S. Raasch and M. Schröter, "PALM-a large-eddy simulation model performing on massively parallel computers," Meteorologische Zeitschrift, vol. 10, no. 5, pp. 363-372, 2001.

[36] I. Esau, "Large-eddy simulations of geophysical turbulent flows with applications to planetary boundary layer research," in Proceedings of the 5th Conference on Computational Mechanics (MekIT '09), B. Skallerud and H. I. Andersson, Eds., pp. 7-37, Tapir Academic Press, 2009.

[37] C. M. Smith and E. D. Skyllingstad, "Numerical simulation of katabatic flow with changing slope angle," Monthly Weather Review, vol. 133, no. 11, pp. 3065-3080, 2005.

[38] S. Axelsen and H. van Dop, "Katabatic flow-the great LargeEddy Simulation challenge," Geophysical Research Abstracts, vol. 8: 02696, 2006.

[39] R. Rotunno, "On the linear theory of the land and sea breeze," Journal of the Atmospheric Sciences, vol. 40, no. 8, pp. 19992009, 1983.

[40] G. A. Dalu and R. A. Pielke, "An analytical study of the sea breeze," Journal of the Atmospheric Sciences, vol. 46, no. 12, pp. 1815-1825, 1989.

[41] Y. Largeron, C. Staquet, and C. Chemel, "Turbulent mixing in a katabatic wind under stable conditions," Meteorologische Zeitschrift, vol. 19, no. 5, pp. 467-480, 2010. 

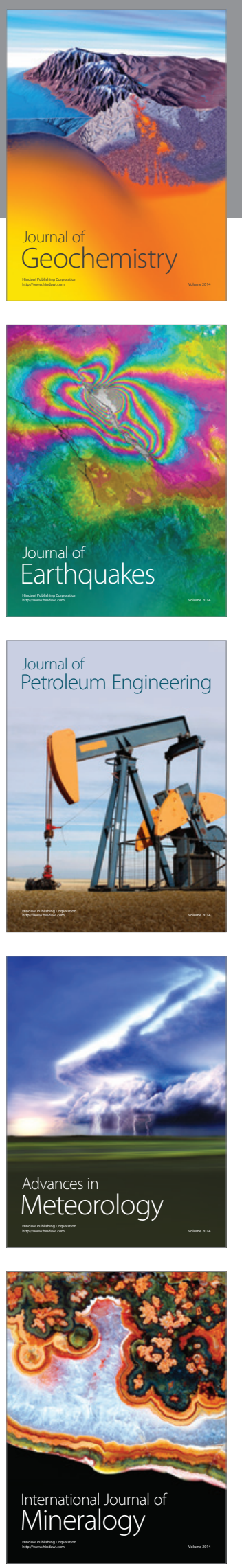
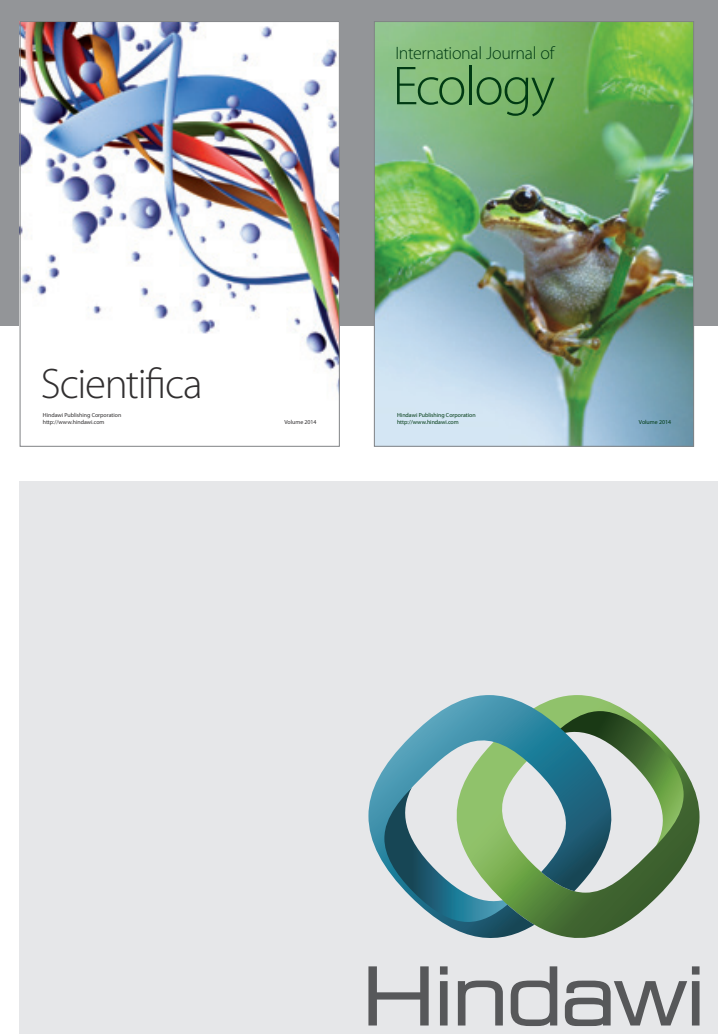

Submit your manuscripts at http://www.hindawi.com
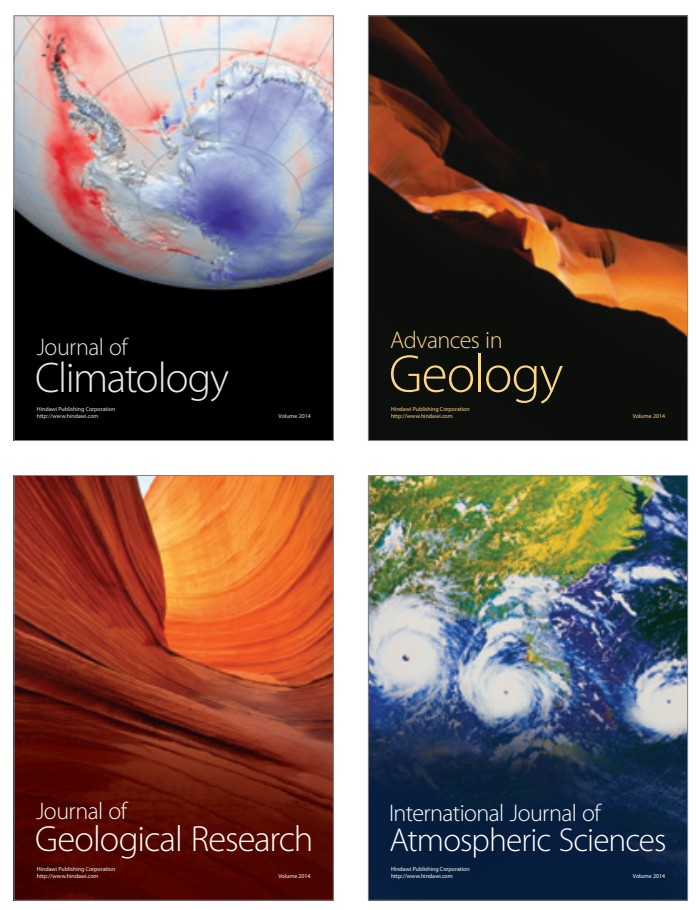
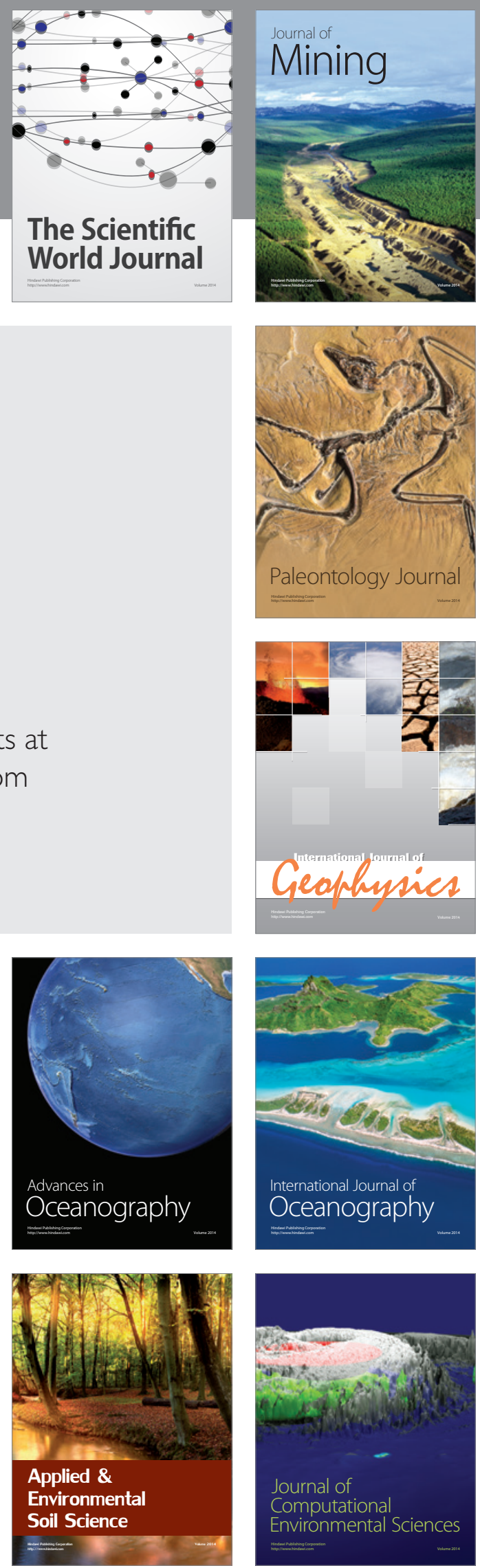